By

James Missen, B.F.A. (York)

A thesis submitted to the Faculty of Graduate Studies and Research in partial fulfillment of the requirements for the degree of Master of Arts in Film Studies.

Department of Film Studies (SSAC) Carleton University

Ottawa, Ontario

April 2002

Copyright (C) 2002, James Missen 
National Library

of Canada

Acquisitions and Bibliographic Services

395 Wellington Street Ottawa ON K1A ON4 Canada
Bibliothèque nationale

du Canada

Acquisitions et

services bibliographiques

395, ne Wellington

Ottawa ON K1A ON4

Canada

Your tive Votre relterence

Our file Notre reilerence

The author has granted a nonexclusive licence allowing the National Library of Canada to reproduce, loan, distribute or sell copies of this thesis in microform, paper or electronic formats.

The author retains ownership of the copyright in this thesis. Neither the thesis nor substantial extracts from it may be printed or otherwise reproduced without the author's permission.
L'auteur a accordé une licence non exclusive permettant à la Bibliothèque nationale du Canada de reproduire, prêter, distribuer ou vendre des copies de cette thèse sous la forme de microfiche/film, de reproduction sur papier ou sur format électronique.

L'auteur conserve la propriété du droit d'auteur qui protège cette thèse. $\mathrm{Ni}$ la thèse ni des extraits substantiels de celle-ci ne doivent être imprimés ou autrement reproduits sans son autorisation. 
The undersigned recommend to the Faculty

of Graduate Studies and Research acceptance of the thesis

\title{
Fringe Experientiality: Canadian Experimental Film and Video as Affective Cultural Theory
}

\author{
submitted by James Missen, B.F.A.,(York)
}

in partial fulfilment of the requirements for the degree of

Master of Arts.
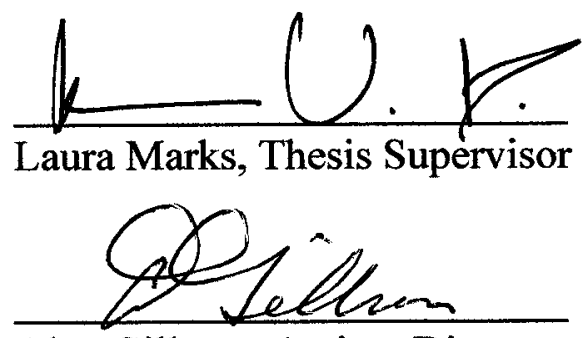

Alan Gillmor, Acting Director

School for Studies in Art and Culture

Carleton University

Ottawa, Ontario

April 2002 


\begin{abstract}
This thesis comprises three interrelated arguments. First, an affective approach to analyzing fringe film and video is the most "useful" way to understanding the experience of marginal media, in that existential phenomenology respects the tensions inherent within the works themselves. Second, fringe films and videos are themselves works of theory that explain and/or express broader phenomena about the society and culture in which Canadians reside. A phenomenological methodology, which emphasizes bodily and sensory response in conjunction with cognitive processes, allows us to see experimental media as works of theory because it allows them to be understood in such a way that we can get the most richness -- of affect, of experience, of "knowledge" -- from them. Third, if we are to try and understand "ourselves" culturally in terms of our multiple identities as Canadians, then this method of experiencing cinema provides a route for trying to conceive of the complexities that comprise "Canadianness" in a nontotalizing kind of way.
\end{abstract}




\section{Acknowledgements}

There are many people who merit recognition for the various ways in which they supported my efforts during the completion of this exhaustive (and exhausting!) project. I would like to begin by thanking my parents Bill and Helen and, by extension, all of my family members (both Missens and Bains, across the generations) for their love and generosity. I am fortunate to be related to people who never questioned what I was doing or why I was doing it, in spite of my inability at times to express exactly what I was up to! Many thanks as well to both Scott Foster and Saaka Minimaana -- my roommates over the last three years -- whose camaraderie and friendly advice I have always appreciated. In particular, I benefited a lot from the sound of Scott's fingers furiously typing out his M.A. Journalism research paper from across the apartment, which often inspired me to get over to the computer and start working on my own ideas.

My deepest respect and thanks goes out to all of the faculty and staff of the Film Studies Department (SSAC) at Carleton University, whose sincere friendliness and enthusiasm for my work has never seemed to diminish since I first walked into the St. Patrick's Building. Similarly, a debt of gratitude is owed to my friends and colleagues from my year of the Master's program - Lee Carruthers, Mary Johnson, Nick Nguyen, Anne Showalter, and Aaron Taylor -- whom I learned from a great deal through our interactions both inside and outside of the classroom. The same must also be said of various Carleton M.A. film students who preceded me, such as Natalie Neill, Marc Raymond, Jose Sanchez, and Charles Tepperman. I should also acknowledge some people whom I've met through participation at various Film Studies Association of Canada conferences who have offered valuable advice and suggestions for my scholarly work. These people include (but are definitely not limited to): Malek Khouri from U. of Calgary; Dave Douglas, Jason Morgan, Thomas Waugh, and Ger Zielinski from Concordia; Gary Kibbins and Susan Lord from Queen's; Liz Czach from Rochester; 
Michael Zryd from U. of Western Ontario; and Janine Marchessault, Theresa Scandiffio, and Darrell Varga from York.

I would also like to thank Ms. Alixe (Pixie) Cram for her support and encouragement during the last few months of this project's completion. I should also acknowledge my colleagues at the Available Light Screening Collective in Ottawa who have provided me with the opportunity to curate various programs of experimental media and are always generous with their helpful comments and criticisms. Finally, I owe a huge amount of gratitude to my thesis supervisor Dr. Laura U. Marks, whose support since my arrival at Carleton has never wavered. Thank you for the dialogues over coffee we've shared, your helpful yet rigorous criticisms of my research, your thorough copy editing, and most importantly, for your patience, dedication, and friendship during the many stressful moments in my life over the past few years. This project is dedicated to the memory of my Aunt Joanne Robinson, a woman who taught me to always be curious about the world around you and never hesitate to have fun while you're engaged in this wonderful thing called "life". 


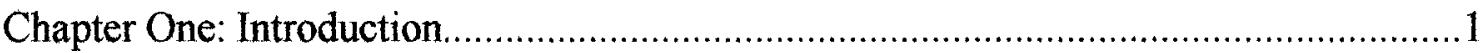

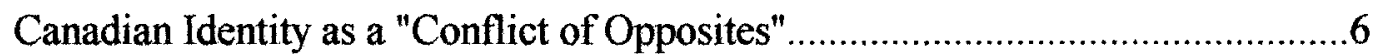

Irony and (Postmodern) Canadian Subjectivities.................................................13

Ironic Intertextuality and the Rupture of Narrative...........................................16

Experimentalism and the Refusal of Conventional "Suture".............................22

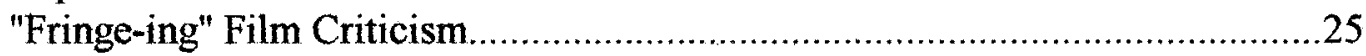

Experimental Media as Experience................................................................29

Chapter Two: Phenomenological Methodology and the Affective Categorization of

Canadian Experimental Media.......................................................................

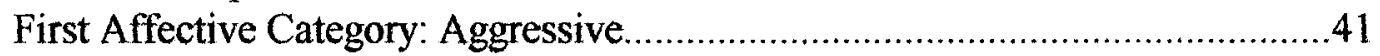

Second Affective Category: Amusing............................................................4

Third Affective Category: Bodily ...............................................................46

Fourth Affective Category: Intellectual..........................................................49

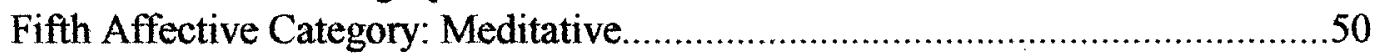

Sixth Affective Category: Monotonous...........................................................52

Seventh Affective Category: Sublime ……………………...........................

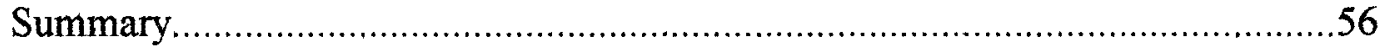

Chapter Three: Experimental Media as (Cultural) Theory...........................................57

Experimentalism and the "Reversal" of History ..............................................61

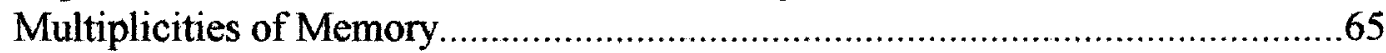

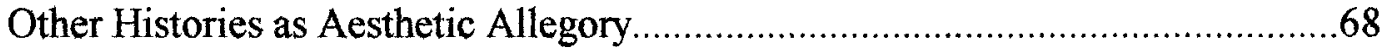

Seeing the "History" of the Present Through the Limits of Video...........................72

Video and Dual/Duelling Consciousness........................................................76

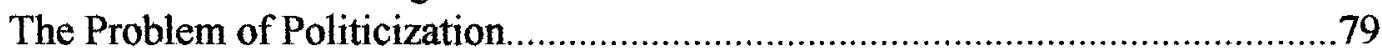

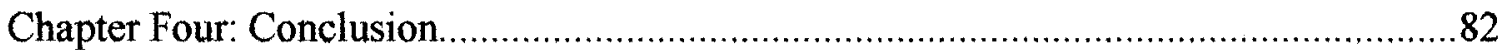

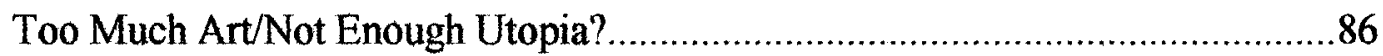

Fringe Art-Making, Digitalism, and the Problem of Capitalism..........................89

The Cultural Value of (Canadian) Fringe Experientiality ..................................91

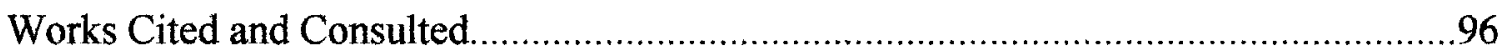

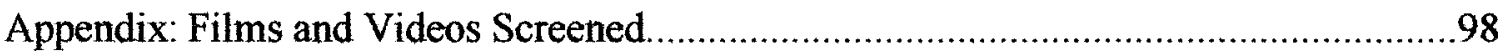




\section{Chapter One: Introduction}

It is striking how, for many years now, identity has been a pervasive theme manifested in the practice of, thinking about, and historicizing of our domestic filmmaking. Embedded in the texts of Canadian experimental film and video of the past few decades is a discourse of fragmented identities, whether individual, collective, or "national". The fringes of recent moving image production in this country proffer numerous conceptual representations of "our" marginal status as Canadian individuals, and as such, merit serious analysis and criticism with respect to how these works shape, liberate, and/or constrain interpretations of "our" culture(s) from both inside and outside our geo-political borders.

In recent years, curators and critics of Canadian fringe media have displayed a fascination not only with the concept of "experimentalism" as it pertains to artistic production, but also with what is distinctively identifiable as "Canadian" in such work. For example, in the program notes for Magnetic North, a touring series of six experimental video screenings held in the Fall of 2001 at the Canadian Museum of Contemporary Photography in Ottawa ${ }^{1}$, curator Jenny Lion writes that, "Many of the tapes in [the program] take risks - risks of offending, of self-revelation or self-assertion, of political commitment, of resisting censorship... or of choosing to entertain in the face of catastrophe. At stake is the act of invention: the process of trying something out, and a willingness to gamble. I use 'experimental' as an inclusive term associated with inventive, often subversive approaches to process, context, or content." I find Lion's comments pleasantly bold, yet also perplexing, as it is unclear to me whether her words

\footnotetext{
${ }^{1}$ This touring program was funded, in part, by the Millennium Arts Fund of the Canada Council for the Arts and was co-ordinated by Lion in conjunction with the Walker Art Center in Minneapolis, MN and Winnipeg, MB's Video Pool Inc. I am very curious as to how these institutional forces impact the contruction of a "national" Canadian video art politic and aesthetic, but that is a research project for another day.
} 
help to shed light on or blur the understanding of either the historical fringe scene in Canada and its contemporary descendants, or the socio-cultural significance of producing and experiencing fringe work. In fact, her choice of language is particularly revealing in terms of how she defines "experimentalism" in a generally closed sense. Recall her assertion that many of Magnetic North's tapes "take risks", and while doing so, acknowledge the fact that she is saying so in the present tense. Is it necessarily so that all fringe works are forever situated in "the times", taking risks in their efforts to subvert or criticize more conventional forms of representation? I would argue no, and interestingly, the exhibition seems to back up this claim, as certain earlier videos in the program such as Al Razutis' 98.3 KHz: (Bridge at electrical storm) (1973) or Pierre Falardeau's Continuons le Combat (1970), might be more accurately described affectively, as having taken risks with respect to the context in which they were originally produced. One of the goals of this thesis is to define such an affective approach.

Certain Canadian fringe audio-visual works evoke the idea that as Canadians we are subjected to speak in a language that is not uniquely our own and, in so doing, further problematize the possibility of identity construction through the distinctive mediums of video and film. "The identity 'Canadian' is nothing 'essential': it is a contingent, precarious identity; something socially constructed. Discursively produced identities are contingent, and ultimately precarious, because the elements of which they are comprised may be subject to different competing (antagonistic) articulations." ${ }^{2}$ Over the years numerous arguments have been made that support the use of various terms in describing fringe films and videos. These descriptive terms range from "underground" to "experimental" to "avant-garde" and appear to shift in time according to the popularity and effectiveness of their usage. My own preference is for the term "fringe" 3 as (for me)

\footnotetext{
${ }^{2}$ Kieran Keohone, "Symptoms of Canada: National Identity and the Theft of National Enjoyment", in Cineaction 28 (1992) p. 24.

${ }^{3}$ I have taken this term from Mike Hoolboom's collection Inside the Pleasure Dome:
} 
it connotes spatiality and situatedness, which creates conceptual linkages in my later assertions about audio-visual media, marginality, and Canadian identity. Fringe films and videos are personal, produced independently, and exist in parallel to more mainstream modes of representation that mark for-profit productions. As well, it would appear that fringe Canadian artists (in)actively resist the tendency to speak in the "American voice" -- or at least attempt to speak outside the limitations of its apparatus -in favour of the positing of "new", alternate filmic forms of speech that call attention to the fractured qualities of its meanings.

There is little critical writing and research that has been dedicated to the evaluation of how fringe audio-visual works in Canada might function as theory which serves to explain broader socio-cultural phenomena. The critical writing that has been done, as evidenced in collections such as Janine Marchessault's Mirror Machine (1995) or Peggy Gale and Lisa Steele's Video re/View (1996), has strong merits, but seems often to be of the kind that bounces about the linear history of the development of the medium and surveys the works of artists produced only within a limited conceptual frame. What results from these studies seems to fall in line with the Frankfurt School's notion of positive criticism, in that merely bringing artists' work into view is a sufficient means for critical analysis. By extension, the consideration of broader meanings inherent in experimental Canadian media are themselves consigned to the margins, appearing mostly in journals, magazines, and gallery publications. Scholarship appears in the form of articles that frequently only focus on one artist or a few works at a time, rarely articulating or speculating about the broader field's over-arching themes and intentions. ${ }^{4}$

Fringe Film in Canada, (Toronto, ON: Gutter Press, 1997).

${ }^{4}$ There are of course exceptions to this critical tendency and I am thinking primarily of two essays by Gary Kibbins entitled "Flaming Creatures: New Tendencies in Canadian Video" and "Bored Bedmates: Art \& Criticism at the Decade's End". In fact, the latter piece makes a similar observation in noting the apparent contemporary divide between art and socio-caltural criticism. The full references for all articles can be found in my 
It is my ambition to treat fringe works in Canada with a little more rigour and. serve them with a level of criticism that it would appear scholars have been doing with mainstream feature film productions in Canada, notably since the late 1960's when critics took the initial steps towards situating a unique, discernible cinematic realism of "our own" within the project of nationalism. That being said, one must also pay heed to the resistant quality of fringe works themselves, in that these artists appear to resist strict categorisation according to societal or artistic movements of the day. Yet, there remains much out on the margins that effectively speaks to and/or about our contemporary status as Canadian peoples and, as such, calls for a renewed critical viewership which is rooted less in solely analyzing the "value" of the object being surveyed. Rather, it is the intent of this project to enact an affective evaluation of numerous, disparate Canadian video art works and experimental films as a means of synthesizing the seemingly "non-sensical" or inaccessible with broader conceptions of understanding the varied culture(s) in which we currently produce ourselves and our experiences of the world.

Thus, my thesis can be stated as three interrelated arguments. First, a phenomenological, affective approach to "analyzing" experimental film and video is the most "useful" way to understanding the experience of marginal media, in that this methodology respects the tensions inherent within the works themselves. Second, fringe films and videos are themselves works of theory that explain, or at the very least, express broader phenomena about the society and culture in which we, as Canadians, reside. A phenomenological approach, which emphasizes bodily and sensory response in conjunction with strictly cognitive processes, allows the viewer to see experimental media as works of theory because it lets them be understood on their own terms in such a way that we can get the most richness - of affect, of experience, of "knowledge" - from them. Third, if we are to even try and understand -"ourselves" in terms of our multiple

bibliography. See also Mike Hoolboom in Rose Lowder, ed. 
cultural identities as Canadians, then this way of experiencing the "cinema we (already) have" 5 provides a route for trying to conceive of the complexities that are "Canadianness" in a non-totalizing kind of way.

In the preparation of this thesis I watched a total of 148 Canadian experimental films and videos made between the years 1970 and 2001. My access to these works was influenced by various factors, most of which pertained to my status as a graduate student of limited financial means living in Ottawa. My primary sources for suitable audiovisual material in the region were found in either the film collection of Carleton University or the video art archives of the National Gallery of Canada. I compensated for the absences implicitly represented in these two primarily "canonical" collections by shipping in preview copies of new work from various out-of-town media distributors (e.g. Vtape and the Canadian Filmmakers' Distribution Centre [CFMDC] in Toronto and Vidéographe in Montréal), as well as attending as many screenings and festivals as possible, including (in Ottawa) the Canadian Film Institute's "Café Ex" series and various Available Light Screening Collective presentations, as well as the iMAGES Festival of Independent Film and Video. These efforts allowed me to not only see some films and tapes which are considered "canonical" enough to appear in institutional collections, but to also look at more contemporary works that would not necessarily be seen in an institutional or academic context. Given the vastness of the body of work that comprises Canadian fringe production, I feel that a "random access" approach to experiencing experimental work is not only the most fruitful in terms of surveying affective

5I am indirectly arguing that Canada already possesses the kind of "cinema we need" that R. Bruce Elder calls for in his infamous essay of the same name in The Canadian Forum, vol. 64:746 (February 1985), pp. 32-35. However, it is my assertion that what we do need is a visceral, phenomenological approach that allows the viewer to get the most out of fringe audio-visual works informed by the shapelessness of Canadian identity. 
response(s), but it was also the most realistic approach given the scope of my project and the limited amount of resources I had at my disposal.

\section{Canadian Identity as a "Conflict of Opposites"}

In the introductory chapter of his 1988 book Canadian Identity, Robin Matthews writes that it seems Canadians worry more about their identity than most other peoples in the world do. He goes on to note how some commentators, regardless of background or national affiliation, believe the "Canadian fixation" is vaguely ridiculous.

But our concern has deep roots and is anything but ridiculous. It has to do with our very survival beside the most powerful imperialist nation in history. Our identity is a matter of forces in tension, of dialectic. [Identity] lives in a process of tension and argument, a conflict of opposites which often stalemate, often are forced to submit to compromise, but which - so far in our history - have not ended in final resolution. As a result, our identity isn't as easy to pin down as we Canadians, and others, would like. ${ }^{6}$

While Matthews is accurate in pointing out that the Canadian fixation with identity is not a ridiculous issue, it does however seem quite ridiculous (or at the very least, problematic) to further a criticism aimed only at deciphering the endless riddle of who "we" are as a nation by trying to render whole the disparate, encoded messages buried in the texts of Canadian feature filmmaking and broadcast television programs. Matthews is misguided in mistakenly holding onto the possibility of a "final resolution" given the "conflict of opposites" that structures Canadian identity. ${ }^{7}$ Still, if this sort of argument is

\footnotetext{
${ }^{6}$ Robin Matthews, Canadian Identity: Major Forces Shaping The Life of a People (Ottawa, ON: Love Printing Service, 1988), p. 1.

${ }^{7} \mathrm{I}$ argue later on in my discussion of Vera Frenkel's videos that the latter two (mainstream movies and TV), because of their form and means of dissemination, attempt to suture viewers into a meaningful whole, which in my view is impossible in the Canadian context. See also footnote 26 for a similar point.
} 
to be made and supported, then perhaps it might best be pursued by looking at ourselves through representations of varied Canadian experiences seen in our experimental film and video productions. For it is these complex works which allude to the nation/state $a s$ is, which is to say in fragments and loosely bound; a fractured nation of multiple, regionalized cultural groups who appear to begrudgingly define themselves in terms of who and/or what they are not.

Similarly, Will Ferguson argues to the effect that if figuring out our own identity as Canadians requires that we "compromise" in using our neighbours to the south as both mirror and counterpoint in determining what "we" (at the very least) are not, then so be it. $^{8}$ He goes on to dispute the rhetoric in tomes by more traditional nationalists such as author and diplomat John W. Holmes, who posits that if Canada ceases to exist, it is more likely to "die by hypnosis" than by foreign investment. Yet at its root, Ferguson's brash and somewhat satirical argument is not unlike the writings of other more sober cultural theorists like Seymour Martin Lipset who, in the preface to his book Continental Divide (1990), recognises that knowledge of either Canada or the United States is the best way to gain insight into the other North American country. "Nations can be understood only in comparative perspective. And the more similar the units being compared, the more possible it should be to isolate the factors responsible for differences between them. Looking intensively at Canada and the United States sheds light on both of them." The idea here is that American culture, particularly in how it is represented in the systems and content of mainstream film and broadcast television, can no longer be entirely ignored if one is determined to truly understand Canada's identity as a nation in a globalized and corporatized world.

\footnotetext{
${ }^{8}$ Ferguson makes this observation in the introduction to his satirical 1997 book Why I Hate Canadians (Toronto, ON: Penguin Books Ltd).

${ }^{9}$ Seymour Martin Lipset, Continental Divide (Toronto, ON: University of Toronto Press, 1990), p. xxiv.
} 
Author Tony Wilden calls for the end to the "collective insanity of Imaginary Canada", which he claims critics have continually imposed on us against our will. $\mathrm{He}$ notes that while some say being (Anglo) Canadian means being a distinctive blend of British and American, others declare that (Anglo) Canada is neither British nor American, whereas some theorists go as far as to say that Canadians, of whatever sort, essentially do not exist.

It as if we dwelt in Notland, where 'being Canadian' meant not being someone else. We have been brought up with an artificial nation, a 'Canada' created by other countries for their own benefit. This Imaginary nation is not the same as the country we actually live in, nor the land we know: the entire 'consciousness industry' in Canada thrives on manipulating this national derangement. ${ }^{10}$

Wilden explains that "Imaginary Canadians" are the only cultural group which are recognizable simply by the number of Other Canadians they consider, whether consciously or unconsciously, to be inferior to themselves, and below them on the various social and economic scales. He lists these Others as: the Québécois, Canadians who don't speak English, and Canadians with "foreign" accents; Maritimers, Westerners, Northerners, and Canadians from small towns; "lower class" Canadian youth, non-white Canadians, female Canadians, and the Canadian working class. Given the nation's current demographic breakdown this seems to suggest that most Canadians are "not real", thus our fringe (or margin) is very broad and loosely defined. In this light, it cannot be refuted that we are not so much the nation formerly known as a colony, but a colonised nation whose "truths" are best explored from the fringe. The works of Canadian multimedia artists enact the discourses of the margins so as to move towards the construction of an affective cinematic language of our own. Still, because the "center"

\footnotetext{
${ }^{10}$ Tony Wilden, The Imaginary Canadian: An Examination For Discovery (Vancouver, BC: Pulp Press, 1980), p. 1.
} 
(of ideology) in Canada is not as stable or visible as it is, say, in the United States, the Others (or some Others) are not so marginal -- or, the fringe for alternative cultural expression is wider.

In this sense historians such as W.L. Morton have described Canada as a strange country that rests on paradoxes and anomalies, governed only by compromise and kept strong only by moderation. According to Linda Hutcheon, living in such a country has engendered in its inhabitants a certain self-deprecating, ironic way of speaking to ourselves and to others.

Obsessed, still, with articulating its identity, Canada often speaks with the forked tongue of irony. Although usually seen as either a defensive tool or an offensive rhetorical weapon, irony - even in the simple sense of saying one thing and meaning another - is also a mode of 'speech' (in any medium) that allows speakers to address and at the same time slyly confront an 'official' discourse: that is, to work within a dominant tradition but also to challenge it - without being utterly co-opted by it. ${ }^{11}$

Just as Northrop Frye is but one of many thinkers who has noticed that Canadians often direct their ironies as much against themselves as against others, Hutcheon goes on to note that Canadians are often said to specialize in a kind of irony that is self-deprecating. "More ingratiating than aggressive, such self-deprecation is said to acknowledge the opinion of the dominant culture -- even appear to confirm it - and allow the speaker or writer to participate in the humorous process without alienating the members of the majority." 12 This quote serves as an initial means of understanding the slyly subversive strategies which encourage particular kinds of viewership in works I will discuss in later chapters. They include (but are not limited to) Steve Reinke's video Afternoon, March

\footnotetext{
${ }^{11}$ Linda Hutcheon, Splitting Images (Toronto, ON: Oxford University Press, 1991), p. 12 . ${ }^{12}$ Ibid. p. 1-2.
} 
22,1999 (1999), Susan C. Rynard's The Day Jesus Melted (1999), and Istvan Kantor's Jericho (1991), all of which are formally and thematically constructed so as to selfdeprecatingly de-position hegemonic (North) American ideologies and biases.

Thus, Canada is best described as a nation in proximity. The multiple $I$ 's which form a discursively constructed Canadian we share (as "our" common defining bond) the lingering awareness that our national consciousness is being surveyed from the outsidein. Much has been written with regard to how the mainstream American cinema appears to problematically engender a system of hegemonic order in which alternate subject positions in film are either effaced or entirely absent. However, its very dominance and popularity as a formal, ideological engine for a naturalized film viewing experience has, for the likes of some Canadian nationalist/realist film scholars such as Peter Harcourt and Seth Feldman, proved difficult to overcome with respect to their ongoing arguments towards a distinctive definition of (a) Canadian cinema. Yet Canadian fringe artists, who make work on the margins of the margin - unlike Canadian feature filmmaking, which is just at the margin -- "make use" of their social, cultural, and political position of marginality so as to enact their works as a means of re-configuring or problematizing dominant North American aesthetics and meanings. ${ }^{13}$ Thus in the current period in North America, "...Culturally marginalized peoples are not simply denied subjectivity. They are, rather, granted a certain (limited) and specific subjectivity that renders them useful by giving them a position in relation to a dominant culture."14 In the context of

\footnotetext{
${ }^{13}$ The question as to which "marginalities" these artists represent is a complex one that I will re-visit later in other chapters. However, it is worth noting that marginality here is multiplicit and could plausibly represent various centre/periphery relations such as: Canadian vs. American identities, non-commercial vs. commercial, and the values of the fringe in general. For example, my supervisor Laura U. Marks has pointed out to me in her extensive notes that "...(Marginality) is not necessarily opposed to a monolithic white maleness, except to the degree that dominant media reflects white maleness."

${ }^{14} \mathrm{John}$ Champagne, The Ethics of Marginality: A New Approach to Gay Studies (Minneapolis, MN: University of Minnesota Press, 1995), p. xxv.
} 
the fringe, Canadianness (as an identity) can be see as a strength, in that its formlessness and fragmentary nature conditions a system of production and reception wherein an alternative cinema can exist without the burden of having to destablize a centre.

A climate to support the production, distribution and exhibition of artists' media in Canada began to crystallize in the late 1960s. This support still comes primarily from government sources at all levels, to a greater degree than in the United States, although in recent years arts grant applicants have been encouraged to maximize private-sector funding. The first section of Marchessault's collection Mirror Machine, entitled 'Institutional Contexts', offers numerous essays that function as a useful summary of the particularities of the Canadian experience as it pertains to government arts funding and financial support for (fringe) media arts. In particular, Marchessault's own essay "Amateur Video and the Challenge for Change" traces the history of how the National Film Board of Canada's Challenge for Change program (instigated in 1967) eventually led to the development of various artist-run centres throughout the nation.

Several video access centres were set up across Canada (Vidéographe, Trinity Square, MetroMedia and Teled among others) to encourage community culture and communication of which video linked to cable television was a central feature. Indeed, many of these access centres -- arguably some of the most productive initiatives of the whole project -- continue to exist very constructively as artist-run organizations. ${ }^{15}$

The phenomenon of the artist-run centre, while not unique to Canada, implicitly bears an influence over most alternative media arts practice and has created distinct conditions for the making of fringe work. In fact, writers such as Kevin Dowler, in a Mirror Machine essay entitled "Institutional Aesthetics and the Politics of Video at the Canada Council", suggest that the history of video art (and by extension, experimental film) in Canada is interwoven with its cultural policy and funding apparatus. However, it is also important

${ }^{15}$ Marchessault, p. 17. 
to emphasize that until the mid-1990s there was a fairly reliable rate of government funding for the media arts, which meant that Canadian artists and organizations could develop their own infrastructure for relatively autonomous production.

Though the video funding program at the Canada Council did not officially begin until 1975, Canadian fringe experimental video and film continues to be made in the context of a federally (under) funded series of communities that are differentiated by region, gender, ethnicity, etc. The Canada Council, which is a federal arts funding body that was instituted in 1957, takes its lead from the two principles of having both an "arm's length" relationship with the government, whereby it can create its own policies and procedures, and a peer assessment system of evaluation that enables artists' funding proposals to be scrutinized by a jury of their colleagues within the discipline. Though they vary from region to region, there are of course other funding agencies throughout Canada at both the provincial and municipal levels that are accessible to producers, distributors and exhibitors of experimental film and video. Conversely, while government funding continues to be an important factor in providing financial resources for artists' media, funding is also (and increasingly) made available by private foundations (e.g. the Daniel Langlois Foundation) and industry sources.

However, the Canada Council is still by far the largest source of money for independent artists and arts organizations, as in 2000 the agency earmarked a total of $\$ 9.9$ million for the media arts. ${ }^{16}$ Furthermore, the institution has realized that "it had to protect freedom of thought and expression or risk creating an official state culture. It was clear that if publicly financed agencies were to encourage cultural and intellectual life,

\footnotetext{
$16 \$ 4.3$ million of this amount went towards individual artists' project grants, whereas the remaining \$5.6 million was directed to media arts organizations dedicated to either the presentation or distribution of Canadian works. The total amount of funding for media arts was third least across all artistic disciplines recognized by the Canada Council and accounted for $11.4 \%$ of its $2000-2001$ budget. These statistics can be found online at www.canadacouncil.ca in a section entitled 'Info-Arts'.
} 
they required freedom to support experimentation and creativity through work that might be critical and challenging." 17 Thus, while it is not my intent with this project to expand on the scholarship of Dowler and others in order to sketch out the complex interrelationship between contemporary Canadian experimental media form, aesthetics, and politics and the institutional apparatus' that support fringe production, I do want to at least acknowledge this history, as government support of artists and artist-run production centres and distribution agencies has played an undeniably strong role in the development of the vibrant and disparate Canadian fringe.

\section{Irony and (Postmodern) Canadian Subjectivities}

The notion of an artist mapping out her/his own marginality is itself paradoxical, for this critical discourse is enacted as a means of interrogating the very idea of maps as systemic sites which are fixed in order to further the dissemination of authoritative knowledge and control. Rather than proposing a "new" totalizing system of representation in place of the old rule, an alternative approach can be found in postmodernism. Postmodern artists, as cartographers of cultures, effectively set out to "map the unmappable"; they incorporate self-reflexive strategies which engender the form and content of their works so as to call attention to notions of fragmentation and multiplicity. Interestingly, these artists do so by making very physical and tangible art forms (be it video and/or film), things wherein the body's presence cannot be ignored, as in practice these works exist so as to be experienced by a subjective viewer. By participating in the screening of experimental works the body is ever-present and active in its relationship with what is on screen, for the perceiving eye confronts itself in the

\footnotetext{
${ }^{17}$ This quote can be found in an online document entitled Peer Assessment at the Canada Council for the Arts: How the Council Makes its Grant Decisions' at www.canadacouncil.ca.
} 
mirror of the work of art, which at the same time serves as a window on the politicised forces which shape our ever-shifting notions of personal and social identities.

To borrow from Patricia Mellencamp, postmodern works do in fact put the relationship of institutions of art, mass media and academia, theories of subjectivity and reception, strategies of narrative and representation, delineations of history, and questions of address and audience, "at stake". ${ }^{18}$ It is the prevailing societal power structure that is held in opposition to the aims of these new alternative forms of imagemaking, which implicitly provide a means to imagine alternate forms of social organization. In writing on Lisa Steele's video art work, Hutcheon posits:

[Her] work, which offers the biographical and autobiographical, private, personal details of women's lives, has been seen as giving "speech to the speechless" - or, more correctly, to those who had been given an absurd, crippled language of desire and description, and had been made to live and work and suffer inside it. ${ }^{19}$

It is the notion of experienced "marginality", self-reflexively acknowledged by artists who are aware of their position(s) outside the traditional socio-political boundaries of culture, that enables a kind of image-making which is up to the task of re-writing the "absurd, crippled language of desire and description." In turn, Hutcheon raises the issue that this condition of marginality, with its attendant qualities of muteness and invisibility, creates in the postmodern artist a divided self rooted in the dualities of culture.

If so, then the 'splitting images' they create through their double-talking ironies are a means of problematizing the humanist ideal (or illusion) of wholeness, as well as hierarchy and power. Contradiction, division, doubleness - these are the contesting elements that let irony in by the front door. ${ }^{20}$

\footnotetext{
${ }^{18}$ Mellencamp makes this assertion in the introductiory chapter of Indiscretions: AvantGarde Film, Video, \& Feminism (Bloomington, IN: Indiana University Press, 1990). ${ }^{19}$ Hutcheon, p. 97.
} 
The key here is this idea of "humanism", which is in itself problematic as it centres around the privileged, male (European) thinker and proposes to explain everything from that perspective without reflecting on its own discursive limitations. Traditionally, the rule of Eurocentric patriarchy has shaped culture in its own image(s), rendering silent the voices of alterity within that society, and limiting the Other(s) to an artificial means of expression which only serves to further the myth of "totality" envisioned by those in recognisable positions of power.

Canadian experimental media artists appear to give an "ironic" voice to the conventionally voiceless, enacting a kind of discourse that explores issues of filmic representation that have traditionally been brushed over by the consuming illusion (and end goal) of Hollywood-type wholeness. Freed from the sort of "burdens" that condition Canadian feature filmmaking (in how these films share a more direct, albeit oppositional relationship with the centre that is the [American] mainstream), marginal works encompass numerous themes largely (de)centred around notions of difference (of gender, identity, etc.) that rarely appear in the image-surfaces of mainstream representations. These artists expose the limits of the apparatus in using the tools of the apparatus itself. Thus, the inherent power structure is de-stabilised and re-shaped by artists who stand (not firmly) as marginal aspects of humanity and society traditionally put under erasure by the powers that (regrettably) be. The idea then is that (especially) Canadian fringe artists exist as multiple dualities, subjected to a persistent self-conscious flux and flow that shifts between re-determining their identities and doing so under the shadow of a society which either deters artists from so doing, or force-feeds them mass cultural denotations of just who and what they should be.

${ }^{20} \mathrm{Ibid}$. 


\section{Ironic Intertextuality and the Rupture of Narrative}

In this respect, image-making on the outskirts of culture echoes the

aforementioned tension between various socio-cultural forces and becomes an ironic (oftsilenced) call to action. Their fragile sounds and images interrogate expectations of the rational and probable, favouring instead a playful strategy which embraces absences and possibilities. The split-self-as-artist enacts an invigorated art which is itself fragmented and loose, and therefore, resists finite definition. Mellencamp writes that in this era of postmodern metamorphosis:

Tangible objects are being replaced by labyrinthian circuitry... the subject is multiple and heterogeneous. Thus, mastery - through vision - over tangible objects and manageable subjects is lessening, as are originals, origins, a real, and singular truths - including the hold of unitary, classical, European systems of thought. 21

For instance, Mike Hoolboom's 16mm film White Museum (1986) speaks for an interrogation of mastery and the cultural tools by which it has been induced. The work is a self-aware subversion of the strategy of traditional Hollywood narrative film structure as a singular truth which the mass North American audience has been conditioned to expect/accept. Quite simply this "anti"-film is a 32-minute projection of clear leader on screen, yet it is the ironic narration of the filmmaker himself, in conjunction with his rich soundscape of plundered Hollywood scores and audio effects, which makes the image/void a means for meditating on possibilities beyond the societal forces which influence a particular work's form and content. His spoken words are meant to be taken at face value (which is interesting here in the context of the face's absence), for there is no visible denotation of identity to attach to the text as a means of fixing its place in the hierarchy. The filmmaker as narrator begins by apologising for his lack of images, citing that "normally after the credits, the film begins". He goes on to comment on his lack of

\footnotetext{
${ }^{21}$ Mellencamp, p. 80.
} 
financing in spite of a continuing urge to have a huge opening filled with explosions. $\mathrm{He}$ remarks, "The cinema is all money... the order and content of images follows the cost of money." Interestingly, the text of the work alludes here to the prospective audience's engendered need to have a particular desire fulfilled through the social act of watching a fictive flow of enticing, spectacular moving pictures.

In remarking that he did in fact gather up the necessary funds for one image, Hoolboom defers the filmmaker/viewer's desire by noting plaintively, "I wanted to save something to look forward to". This echoes his consideration of narrative closure as comparative to "closing a book", as something that the audience "can hold on to" once their anticipation is brought to a fulfilling and affirmative climax. The implication here is that perhaps closure comes at the expense of contemplating multiple levels of identity, as it must be enacted by "recognizable" characters who affirm types of values which are determinable and sanctioned by the socially powerful. Interestingly the narrator posits, "The time has come for a cinema without images... our own". The classical idea of cinema remains sutured to the idea of an image as a totality which can be seen, and therefore, known. Yet, the postmodern logic of Hoolboom's White Museum considers absence as presence and, therefore, frees itself to wonder about the possibility of seeing the "unseen". The narrator alludes to the white screen as the sheet on a lover's bed, a magnified hair grown too old not to remember, the wall of an asylum, and the beginning of writing, and imagines "...A society without language, for only by adding nouns do certain acts describe themselves."

The idea here is that language itself is constructed by those in power in order to facilitate an easy, finite way of knowing and, as in the case of many of the issues problematized in Lisa Steele's video work, constructing finite notions of the feminine as Other in culture. In the same way that Hoolboom's work challenges conventional strategies enacted in narrative cinema, Steele's Birthday Suit with Scars and Defects (1974) stands in direct confrontation with traditional authoritative views about "knowing" 
women. The tape is a well-known early performance piece in which the artist recalls the narrative of her life thus far on the occasion of her 26th birthday. She displays, in chronological order, her body's collection of scars for the surveying gaze of the video camera. This is done in a matter that is both systematic and sensuous, such that her skin is presented as de-erotocized spectacle. The artist's body is re-written as text, as a site of production, which is re-constructed so as to deflect the look of the male viewer.

Whatever pleasure to be gleaned in Steele's (tape)
does not reside with the body as a mediated object,
but with a pathological attention projeeted onto an
imperfect subject. Displacing the female body of
classical cinema, who undresses by taking off her
glasses and thereby transfixing the spectator
symbolically through her gaze, Lisa Steele offers
herself, her naked body, her scars, and her defects
to an almost painful level of scrutiny.

The narrative of the artist's life is, to borrow from the title of Jeanette Winterson's novel, "written on the body" in the sum of its wounds and scars. Dot Tuer's idea of "projecting a pathological attention onto an imperfect subject" is key to understanding the formal, thematic, and discursive strategies enacted throughout the limitless "body" of Canadian video art tapes. Steele's work draws our attention to multiple, imperfect bodies rather than a single, falsely idealized one.

Steele's attention to detail and her scrutinization of surfaces reveals the impossibility of "properly" documenting the complex experiences of life. For instance, her 1975 video Facing South sets itself up as a visual journal of an early spring growing season. The video is a diaristic look into the life of a woman artist at home and the ways in which her body and identity intersect with/diverge from the natural elements of her environment. The tape begins with her slow voice-over assertion: "Sometimes I look at

\footnotetext{
${ }^{22}$ Dot Tuer, "Mirroring Identities: Two Decades of Video Art in English Canada", in Mirror Machine: Video and Identity, Janine Marchessault, ed. (Toronto, ON: YYZ Books \& CRCCII, 1995), p. 111.
} 
things too closely, seeing them in too much detail." However, when her video camera sees the "real" world in extreme close-up the details of this environment are rendered "unnatural". The motif of the magnifying glass, which is symbolic of rationality and the progress of scientific thought, is inverted and used here to further complicate and confuse denotations of the real and unreal, and what are presumed to be the known and unknown. It is as if the closer one looks at the representation of a subject with the tools of mastery, the more the original sense of that subject is lost on its viewer. Interestingly, when the camera lens turns to her own genitals, the narrator/artist comments, "Seeing here clearly is difficult, even under magnification", as if reflecting on the complications in determining this particular site of the female body free of its construction as a site of sexualised desire. Steele has written that she intended the tape to reflect on the unreliability of paralleling female experience and cycles in nature, ${ }^{23}$ offering instead an analytical and feminine approach which implicitly re-determines cultural denotations of women as inherently "natural". Here, the female artist is shown literally to be the gardener and not the figurative garden, for while she interacts with various "natural" sites during the course of the 22-minute video, Steele does not represent herself as exclusively belonging to that realm. Rather, she is the analyst/artist who literally eats the leaves of plants she has watered and plays with the captive turtles she feeds.

Canadian fringe moving image works exhibit a certain irony in playing with the textual conventions of what is to be expected when watching visual representations of reality unfold before the human eye of the audience. Whether evidenced in such disparate works as Steele's re-determination of the genre of the 'cop show' in 1982's Some Call It Bad Luck, Hoolboom's fan letter to Madonna's cult of celebrity in Justify My Love (1994), Rynard's dark satirical take on the corporate infomercial in Eight Men Called Eugene (1996), or John Watt's post-apocalyptic breakdance video Nuclear Breakdown

\footnotetext{
${ }^{23}$ Video Reference Guide Catalogued by Vtape (Toronto, ON: Vtape, 1996), p. 182.
} 
(1984), the practice of postmodern image-making often involves a strategy of ironic intertextuality. Fringe artists choose how to navigate socio-political circumstance so as to develop a special aptitude for double-speak which aspires to represent their status as culturally multiplicit. Hutcheon argues that intertextuality functions in two ways:

On the one hand, it marks a rupture with, or at least a subversion or critique of, the text parodied; on the other, it establishes a community of discourse among readers and thus marks a kind of interpretive continuity. With continuity, of course, comes what many see as the elitist pleasure of irony and parody: the pleasure of being among the initiate, of possessing the requisite knowledge to 'get' the joke. But ironic citation is also a way of exploring the history of visual and linguistic representations of identity; its deconstructing power can show up the often unconscious but deeply embedded sexist premises that underlie those representations. ${ }^{24}$

In this respect, Steele's 1982 work Some Call It Bad Luck uses the convention of a television police drama which is ruptured from the expected so as to call attention to the absence of any dramatic action. Her "characters" just end up carrying on one interrogation room conversation after another. Steele herself describes the tape as an examination of how order and authority reproduce themselves as domineering social structures, developing an account of reality that differs greatly from the lives of the powerless people that those "official conclusions" supposedly describe. ${ }^{25}$ Ironically the protagonist's "true" story is not, and never will be, heard by the police because of the forceful strategy which impacts the way her narrative is to be revealed in the tape: interrogation. In turn, the particular type of questioning which "Donna" endures subjects her story to a false sense of representation, wherein woman as the victim of crime is cast by those in social authority as criminal. The police here are representative of deeper

\footnotetext{
${ }^{24}$ Hutcheon, p. 96.

${ }^{25}$ Video Reference Guide Catalogued by Vtape, p. 182.
} 
forces in patriarchal society; they drive to implicate, to substantiate suspicion as belief, and to fix meaning and understanding to the empirical facts of the case of narrativity.

In another work of ironic intertextuality, Hooboom's Justify My Love, the enigmatic letter-writer Jason has amassed a body of "objective" knowledge by collecting all of his supposed high school lover Madonna's "magazine interviews and records, so I can remember where you've been." The tape is a plundered duplicate of Madonna's rock video of the same name, though Hoolboom imposes a black bar across the bottom of the screen for the scrolling text of Jason's fan letter. Although the viewer never sees Jason, we seem to learn a lot about his body, or at least his sexuality, through the interplay between the fetishistic black and white images of Madonna and his stream of consciousness musings. The work posits an inherent competition for audience attention between the sexualised visuals of the mainstream rock video and the personal written text, such that the original site(s) of address are effaced. One section of the letter remarks to the iconic celebrity as addressee "The body doesn't stop at the skin." Ironically, the "body" of the letter that scans across the lower third of the screen is as sexually charged as the fetishistic images that form the content of the rock video itself. The concept here is not unlike Steele's tape in that Hoolboom is pulling for his audience to "get" his rather unsettling joke (to borrow Hutcheon's terms), by considering the notion that personal and social identity can be (and most often is) determined by the inefficacy of the constructed things of the mass, usually from elsewhere. Furthermore, Hoolboom's obsessive loser figure Jason can be read as slyly juxtaposed to that of Madonna the mass media icon and, in this context, works to reinforce notions of Canadianness as "not"being, as being in the shadow of other larger socio-economic forces. However, it is worth noting the significance of bootlegging the Madonna video in this context, as effectively Hoolboom sutures his meaning into the mass media text as a means of expanding his agency and his means of expressing his identity. Both artists' works inherently counterpose public knowledge and private, bodily experience, which 
effectively delimits the possibility of considering alternatives to the sense of "wholeness" seen in mainstream media representation.

\section{Experimentalism and the Refusal of Conventional "Suture"}

In a certain respect then, experimental film and video works call attention to the notion that the classic discursive strategy of suture, a means of forming a seamless conceptual junction between the two disparate yet contiguous surfaces of "fiction" and "reality", only serves to complicate the already difficult process of identity representation. When considered alongside the ideas of Beverle Houston (as cited by Kay Armatage), who posits that the classic Hollywood text is constructed so as to smooth over the play of absence/presence, ${ }^{26}$ what becomes clear is that in undermining this suturing effect, Canadian experimental film and video art interrogate the limits of the ideological framework imposed on narrative by the myth makers and storytellers of commercial (North) American cinema. This is to say that these artists' anti-strategies to classical suture inform a playful multi-layered position whereby the text and structure of the work self-consciously acknowledges presence as absence, and vice versa, ad infinitum. For instance, Vera Frenkel's tapes and installations, of which the faux detective story Introduction to Some of the Players (1977) and ...And Now the Truth (A Parenthesis) (1980) are early examples, dismantle the way spectatorial identification is conditioned as a voyeuristic site of control over culturally recognisable "characters".

The art of Vera Frenkel, while it undoubtedly addresses feminist and postcolonialist concerns, seems to speak more towards the overriding post-modern distrust of the differences between socially constructed notions of truth and fiction. If one could define suture in the simplest of terms as sewing, then it is interesting to consider how

${ }^{26}$ This argument is cited by Kay Armatage in her essay "The Body-That-Disappears-IntoThin-Air: Vera Frenkel's Video Art" which appears in the collection Mirror Machine: Video and Identity, pp. 67-88. 
culturally composed ideas of truth are a finely stitched quilt; some of them are facts, some of them are stories, and some of them are lies. As an artist Frenkel concerns herself with how we acquire knowledge, how we come to decide what is truth and what is fiction, and how we come to believe some stories and not others. Whereas the classic Hollywood text depends on the belief that by ideologically stitching together particular facts, stories, and lies, a wholeness (of inherent absences) can be achieved wherein narrativity translates as "truth", Frenkel's video art, and other examples such as Stan Douglas' video installation Win, Place, or Show (1998) seem to point out that rendering the particulars of any ideological perspective whole via these strategies is a process fraught with paradox. In fact, Douglas' piece does so in a literal manner, as he divides the screen of his site-specific work into four fragments such that his images of two male actors carrying on an argument as they place bets on a horse race are never visually coherent. Douglas creates spatial and temporal fragmentation with the use of digital technology which selects the projected video images from the thousands he compiled during his original multi-camera, multi-take location shoot. Consequently, the wholeness of the screen -- and by association, the narrative - is never fully discernible, as every iteration of the 5-minute loop is rendered different through the randomness of the projector's selections. In the same spirit, within the narration of her tape ...And Now the Truth (A Parenthesis), Frenkel remarks, "The truth is not a story"; the truth cannot exist in principle as a totality of stitched patches, so to speak.

Frenkel interrogates the means by which contemporary society's acquired "knowledge" has been informed by culturally codified means of storytelling, whose essential goal is to perpetuate the spectator's false sense of how knowledge is acquired by way of narrative. Her video detective stories are an example of this tendency, as they do not in fact lead anywhere, but rather question the validity of using the logic of cause and effect in order to construct narrative wholeness. An essay by Lisa Steele, written in conjunction with a National Gallery of Canada survey exhibition of Vera Frenkel's art, 
raises the question: If we are not to obtain the "truth" easily, then where are we as a "collective social audience" (which is - and paradoxically, cannot be - reduced to a mere sum of its unique parts), to seek it? ${ }^{27}$ This is the sub-structure of all of Frenkel's work - a poetic but thorough examination of human memory, both individual and collective, because here lies the key to what is kept and cherished.

In acknowledging the formative power of received ideas and the problematic ways in which ideas have historically been transferred/received, Frenkel's art expounds the fragility of human memory as it frees/confines pre-set ideas of fact and fiction. Her juxtaposition of particular cultural formats and loose genres only serves to reveal the contradictions between several sets of received ideas and does not propose to speak to any authoritative truth claim. Unlike the strategies of the classic Hollywood text, the "characters" in Frenkel's tapes exist more as windows than as reconstructed positions for spectatorial identification. If, as an audience, we faithfully accept the narrator in Introduction to Some of the Players to be the "perfect" investigator she claims to be who states that "there are no false clues", then the photo of Sam Broom and the description of him as a "good/bad boy" refuses to ascribe identity with fixed meanings. As one of "some of the players" Sam exists only structurally in conjunction with the other "characters", as transparent openings both absent and present, through which the viewer accesses Frenkel's complex web of interwoven narratives and layered texts.

Frenkel's tape ...And Now the Truth (A Parenthesis), the first video in a series of works entitled No Solution - A Suspense Thriller, speaks to how the classic Hollywood text is set up to consider all the "possibilities" it evokes within the closed confines of linear narrative structure for its audience. Upon an initial viewing of the work, one might describe the process of navigating the layers of fractured images and multi-textual voice-

\footnotetext{
${ }^{27}$ Lisa Steele, "Committing Memory", Vera Frenkel (Ottawa, ON: National Gallery of Canada, 1985).
} 
overs as uncomfortable, but that is entirely what is intended. To borrow from Frenkel's words, as artist/actor/narrator, that permeate the film's pastiche-like structure, "Have we not understood, my darlings, that the truth cannot be told?... That the truth is shaped, cosseted, abridged, revised, negotiated, denied, remembered, mis-remembered, approximated, and attributed to one falsehood after another? That in our longing for truth, we embrace those falsehoods? And, that we prefer it so?" In this respect, Frenkel as artist undermines the suturing effect that has confused our problematic human longing for truth with the multiple facets of what "truth" could be considered to be, favouring instead the multiple representations of an infinite number of disparate fictive and real surfaces. Her work delights in recognizing that any ideological discourse engaged in the search for "truth" both simultaneously and paradoxically embraces falsehoods, and therefore, the structure and process of art engaged in the telling of stories must somehow approach the fragmented mirror of identities.

In short, the situation of Canadian fringe media artists on the margins of the traditional socio-political map makes irony a powerful rhetorical/discursive tool in "dismantling" strategies of mastery from the inside-out. The contrasting elements of contradiction, division, and doubleness service a kind of image-making which is unlike that of more mainstream cinema that precedes (and continually informs) fringe strategies of visual and ideological representation. The postmodern "narratives" of Hoolboom, Steele, and Frenkel and their inherent subjects, which are themselves fragments and without finite boundaries, oppose classical suture in determining a new kind of narrativity which disrupts the function of closure and pre-conditioned desire.

\section{"Fringe-ing" Film Criticism}

In a broad sense, critical writing and thinking about film often serves what could be called a "totalizing purpose" designed to smooth over difference. This is to say that even though film criticism is often resigned to speaking about a handful of films at a 
particular time, there seems to be an implicit desire on the part of the analyst/critic to pull things together so to speak, or to make sense of it all. Often specific case studies of films are enacted merely as evidence that the over-arching theories at play therein are justified and correct. Studies dedicated to fringe media are themselves not exempt from this kind of thinking, as evidenced by books such as Edward S. Small's Direct Theory: Experimental Film/Video As Major Genre (1995), whose thesis is problematically grounded in the notion that experimental films and videos share combinations of eight characteristics. He lists them as: "brevity, acollaborative construction, economic independence, non-narrative strategies, an avoidance of verbal language, the phenomenology of mental imagery, an affinity for ongoing technological innovation, and a pronounced reflexivity." 28 However, what methodologies such as Small's often overlook, downplay, or at the very least misconsider in the interaction that occurs between viewer/thinker and filmic text is the very notion that $\mathrm{s} / \mathrm{he}$ who approaches the works is a perceiving subject, an individual inhabiting a unique position as a viewing/experiencing spectator. I will look at Small's thesis in more detail later; however, it should be noted that to define experimental media as a genre inherently limits the potential for greater critical inquiries, as in my estimation this eliminates considering other categories for the classification of fringe productions, such as to look at them as phenomenological processes, socio-cultural phenomena, or a politicized practice of form and aesthetics.

What then can be said of the viewer/participant who approaches these artistic works, and specifically, is there something inherent in the art video or the experimental film that collapses or problematizes the drive towards "totalization"? What I mean by this is that in regard to the (by no means exhaustive list of) works by Canadian artists

\footnotetext{
${ }^{28}$ Edward S. Small, Direct Theory: Experimental Film as Major Genre (Carbondale, IL: Southern Illinois University Press, 1994), p. 87.
} 
over a thirty-year period that I have surveyed ${ }^{29}$, there is a discernible pattern as to the kinds of engagement with the viewer/participant that occur therein. What immediately comes to mind when trying to posit any kind of overview of these works is their unlikeness, be it through the disparate manifestations (as seen across Hoolboom's four generations of the and others since $)^{30}$ of content, aesthetics, form, structure, or what have you in each separate work. Yet, in spite of the inherent disparity amongst Canadian fringe productions, Atom Egoyan sees a principled similarity amongst all of its makers, "not simply because of the extraordinary quality of their work, but also, and perhaps more profoundly, because of the ceaselessly curious and completely trusting nature of the audience they've had to imagine for their creative efforts." 31 Thus, it would seem that there is more at work here in terms of similarities than the mere observation that the works are being made by Canadian artists in such a way that is marginally different or "alternative" to the conventional production of audio image-texts. Egoyan summarizes this point in the same piece by noting, "Fringe films address, liberated from the moderating influence of narrative, our purest sense of impulse - the way we see. To treat these films as marginal is to marginalize some integral part of ourselves." 32 Curiously, by the mid- to late $1980 \mathrm{~s}$, the discourse of experimental film and video production appeared to have moved away from (or at least expanded on and refined) its

${ }^{29}$ Recall my earlier discussion of arts funding from the Canada Council. Again, even though media arts support from the federal govenment had not been concretized until 1975 , it had appeared in the form of 'Challenge for Change' by the late 1960s. Thus, I have used 1970 as a loose departure point for defnining my object(s) of study. ${ }^{30}$ Hoolboom traces a lineage of Canada's filmmakers in his essay "A History of the Canadian Ante in Film", in The Visual Aspect: Recent Canadian Experimental Films, Rose Lowder, ed., (Editions. Des Archives du Film Experimental d'Avignon, 1991), pp. 29-45. While I find his description incredibly useful, it is important to note that as with any "history" there are always gaps and overlaps. The Canadian fringe (or the regard.

${ }^{31}$ Atom Egoyan, "Foreword", in Hoolboom, ed., p. 1.

${ }^{32}$ Ibid. 
original argument that this work is unique and most culturally "valuable" or significant in its polarisation from mainstream ideology and aesthetics. Fringe media's cultural value exceeds the fact that it is different from, or opposed to, a dominant Other.

How then might one draw affinities, parallels, or connections in the study of Canada's fringe cinema without setting aside critical respect for each work as a unique artistic project in and of itself? This distinction seems crucial as, unlike more conventional understandings of authorship inherent in the academic discourse of film studies, it would seem that the fringe artist challenges discernible relationships between the author and her/his own body of work(s). One could make the argument that, just as with mainstream production, the Canadian video artist or experimental filmmaker brings her/his own personal interests in particular themes, styles, etc. to each of their works. However, I would argue that to survey any of these artists' larger bodies of artistic output reveals more departures from a centrally grounded auteurist system of logic than anything else. And yet again, more accepted modes of thinking would oblige us to make sense of all of the parts of a text or a body of an artist's work so as to pull things together, rendering the moving image immobile and surveyable. Writing and thinking about these self-consciously mobile, shifting works is difficult to carry out when there is somewhat of a critical uncertainty as to how these films and videos are best analyzed: as art objects, as cultural phenomena, as political interventions, as expressions of identity, etc. How then to balance out the aforementioned totalizing sensibility - the will to "make sense" -with an effort to write about these works within a critical language that seems in keeping with the fluctuating concerns of the artists themselves?

The intent of this project then is not (necessarily) to challenge more conventional thinking about fringe film and video, but rather to attempt to move experimental works into a realm of critical thought that emphasizes the importance of analyzing and understanding how fringe film and video works are individually (and culturally) experienced. Thus, the fringe audio-visual work should be considered neither as an 
object that offers access upon its critical observation to finite kinds of knowledge or information, nor as a thing that is unique merely in its positioning as being "different" from or unlike a conventional film. Again, my intent here is to enact this survey of Canadian experimental films and video art works as a necessary engagement with audioimage works at the experiential level. In this regard, consider the following passage:

When we sit in a movie theater and perceive a film as sensible, we (and the film before us) are immersed in a world and in an activity of visual being. The experience is as familiar as it is intense, and it is marked by the way in which significance and the act of signifying are directly felt, sensuously available to the viewer. The embodied activity of perception and expression - making sense and signifying it - are given to us as modalities of a single experience of being in the presence of and producing meaning and value. ${ }^{33}$

Here then is a marked return to the importance of the body as a sensing entity and the reinstatement of the significance of the subject as a perceiving spectator, which (perhaps not coincidentally) is a theme that is explicitly manifested throughout Canadian art videos as diverse as Paula Levine's Mirror Mirror (1987), Rodney Werden's May I/Can I (1977) or Shauna Beharry's Seeing Is Believing (1991), just to name a few.

\section{Experimental Media as Experience}

What this signals is a transition to the subject and the study of film as one which should be phenomenologically or experientially based. Interestingly, this mode of thinking about cinema as an experience does not efface the importance of the author or his/her object, inasmuch as it pays respect to the position of the (Canadian) film/video artist as one who is self-reflexively downplaying her/his own authorial role at the level of production. In this regard Small quotes theorist Robert Stam, who in his study

\footnotetext{
${ }^{33}$ Vivian Sobchack, The Address of the Eye: Phenomenology and the Film Experience (Princeton, NJ: Princeton University Press, 1992), p. 8.
} 
Reflexivity in Film and Literature (1992) poses the question: How can the cinema illuminate its own specific textual processes? "The penchant for reflexivity might be seen as symptomatic of the methodological self-scrutiny typical of contemporary thought, its tendency to examine its own terms and procedures. Thus we find reflexivity forming parts of diverse fields and universes of discourse. ${ }^{34}$ Reflexivity not only functions so as to initiate an examination of the ways in which the fringe producer makes work, but also radiates outwards so as to cue perceiving spectators to be flexible in their own bodily and mental interactions with what their senses take in from experimental works.

Generally speaking, if there is but one comment that can be made with respect to the films and videos I have surveyed, it is that each artist appears to enact her/his audiovisual works in such a way as to invite the viewer's participatory experience: It has been said of Canadian fringe media that "The images have to provide an experience which amounts to more than what is seen under usual circumstances; the practice has to develop processes for presenting images and for extending the manner to which they evolve sufficiently for the viewer to engage in a perceptual process not normally undertaken." ${ }^{35}$ It can be argued then that this process of engaging the viewer of Canadian experimental film and video art in a "perceptual process not normally undertaken" is accomplished formally and thematically in numerous ways, such as playing with form and structure, challenging relationships between image and audio, or self-consciously problematizing the texts' own ideological position. However, it would seem that the overall emphasis is placed on an awareness by the artist that these works are being made to be meaningful. This fosters the kind of symbiotic relationship between engaged, participatory subject and object/text to which Egoyan's quote alludes. Yet what makes this kind of experiencing by a viewing subject distinct from any other kind of cinematic experience?

\footnotetext{
${ }^{34}$ Small, p. 103.

${ }^{35}$ Rose Lowder, "Another Level of Perception", in Lowder, ed. p. 76.
} 
And furthermore, is there anything "Canadian" about this cultural exchange between selfeffaced artist/author and experiencing audience? The answer to both questions lies in the "non-sense", a concept that first emerges in the writings of philosopher Maurice MerleauPonty, and which is also developed by Gilles Deleuze.

Non-sense is a notion which offers much more than mere nonsense, if you will, and I will expand on the idea in detail in later chapters. Deleuze's dense book The Logic of Sense (1969) equates non-sense with anti-idealism. By extension, my estimation of non-sense is that it comprises feelings, ideas, etc. that are themselves marginalized from conventional modes of understanding; it is the sentiments and thoughts outside of the route to determining "useful", empirical knowledge. ${ }^{36}$ Thus, non-sense does not imply the mere destruction of logic and sense, inasmuch as it invites a newness of approach by problematizing the conventional associations we make between sensory observation and actions in or judgements about the world. Through the study of Canadian experimental film as individualized experiences that may lead to alternate modes of thought, the perceiving critic may usefully rely on non-sense in order to "make sense" of these works, without abandoning the awareness of their status as marginal. Furthermore, this notion of non-sense seems in keeping with the idea that Canadianness involves engendering cultural meaning through marginal artistic production, which Hutcheon develops through her comments on the function of irony. For it seems that as a nation we are continually obliged to think of ourselves as whole via means that are not our own. "The problem of Canadian unity is one of identification: i.e., of leading a diverse collectivity to a mutual recognition of a shared relationship to something called 'the Nation". 37

\footnotetext{
${ }^{36}$ I am thinking also of how Merleau-Ponty describes the notion of "non-sense" as prior to and always potentially disruptive of order and rationality. Thanks to Prof. Charles O'Brien of Carleton University for noting how this is found in Sense and Non-Sense, trans. Hubert L. and Patricia Allen Dreyfus, (Chicago, IL: Northwestern University Press, 1964).

${ }^{37}$ Keohone, p. 20.
} 
The alternative that non-sense poses to making sense of cinematic texts only in order to confirm already-held "logical" assumptions, leads me to the beginnings of an affective approach to viewership. This methodology serves to emphasise the importance of the study of one's experience of audio-visual objects in tandem with the objects themselves. It is a process that seems to point out intersections as much as polarities between the works being seen, heard, and felt. This methodology is thus a "non-sensical" analysis/understanding of how experimental works impress upon the viewer as a perceiving participant, and it requires me continually to be aware of my role in that symbiotic relationship. What follow are seven initial categories of classification which function primarily as an extension of this project, a venture which is aimed at disseminating meaning(s) from the survey of the bodies of Canadian fringe film and video of the past three decades. The categorization of these works as aggressive, amusing, bodily, intellectual, meditative, monotonous, and sublime, is pertinent. These affective categories are points of departure which allow me to examine my own relationship to the texts before aspiring to pull together the fragments of Canadian fringe production into a larger assertion about the relationship between these marginal audio image-texts and the broader cultural context(s) of this country. Also, I find this investigation intriguing with respect to author J.G. Ballard's curious categorization of the latter part of the 20th century as an era haunted by "the death of affect." ${ }^{138}$ Does the experimental film and/or art video not only reflect and comment on this situation but also work towards the development of "new" affective possibilities for the thinking/feeling viewer? Working with the fragments of my experience of the filmic fragments, I am choosing the task of pulling it all together in terms of an affective interaction with fringe artists' work. In sum, my concerns revolve around using phenomenology in order to

${ }^{38}$ Ballard makes this observation as he examines what motivates his fiction writing in his 1974 essay "Introduction to Crash", which has been reprinted in the subculture magazine Re/Search, Nos. 8/9, (1984). 
identify Canadianness through references to individual fringe works that call upon affect in such a way that avoids critical "totalization", yet still leaves me with a vibrant method of investigation. 
Chapter Two - Phenomenological Methodology and the Affective Categorization of Canadian Experimental Media

What I am proposing is a theory of "fringe experientiality" built on phenomenology, so as to move towards an argument about how this particular kind of film and video viewership might construct meaning and understanding for the culture(s) by and for which fringe works are produced. As such, one particular avenue for understanding experimental works as meaningful, while still respecting the inherent qualities which condition their marginality, is to experience them as being non-sensical, which maintains the embodied quality of the works and is, arguably, the most "Canadian" thing about them. To experience these works as non-sense maintains the phenomenological tension of what is seen and heard in a fringe production, and refuses to reduce the experience of the work to a strictly cognitive one. This approach supports the understanding of fringe works as meaningful theoretical and cultural phenomena, precisely because they resist being incorporated within the politics and aesthetics of the normalizing centre.

In her writings on the philosophical project of phenomenology and the experience of film found in the 1992 book The Address of the Eye, theorist Vivian Sobchack reinvigorates the philosophy of Maurice Merleau-Ponty to note that the moving picture makes itself sensuously and sensibly manifest as the expression of experience by experience. She writes that "A film is an act of seeing that makes itself seen, an act of hearing that makes itself heard, an act of physical and reflective movement that makes itself reflexively feit and understood." 1 This is to say the cinema (and I include video here), as individually experienced artifice, signifies in an embodied language that which presupposes what Sobchack describes as more discrete, systematic communication. "Cinema thus transposes, without completely transforming, those modes of being alive

\footnotetext{
${ }^{1}$ Vivian Sobchack, The Address of the Eye: Phenomenology and the Film Experience (Princeton, NJ: Princeton University Press, 1992), p. 3-4.
} 
and consciously embodied in the world that count for each of us as direct experience." 2 Therefore, by Sobchack's critical estimation, the work of film has the capacity to signify; to not only have sense, but also to make sense through a unique and systemic form of embodied communication.

I am aware that my methodological approach to experiencing fringe works shares certain things in common with cognitive film theory, though I should note here how my understanding of affect, via phenomenology, is different. My approach does converge with cognitivism in the way that I am interested in how viewers make sense of a work. Thus, I agree with James Peterson's assertion that cognitive processes are part of the viewer's experience of all avant-garde film, though I dispute his claim that they are central to the viewer's experience.

My objective here is, in a sense, the reverse of $(\mathrm{P}$. Adams) Sitney's: I want to show not how the avantgarde cinema reproduces the mind, but how the mind comprehends the avant-garde cinema. The crux of my argument is that we might usefully consider avant-garde film viewing to be a kind of problem solving, which cognitive theories can help explain. ${ }^{3}$

However, my methodology diverges from cognitive film theory in that I understand "making sense" of a work in terms of my particular subjective location, which is an approach best served by existential phenomenology. ${ }^{4}$ Much like Sobchack, I wish to

$2_{\text {Ibid, p. } 4 .}$

${ }^{3}$ James Peterson, "Is a Cognitive Approach to the Avant-garde Cinema Perverse?", in Post-Theory: Reconstructing Film Studies, David Bordwell and Noel Carroll, ed. (Madison, WI: University of Wisconsin Press), p. 109.

${ }^{4}$ I should note that scholarly proposals for a phenomenological approach to experimental media have been around since the late 1960s and early 1970 s. However, my approach differs from, say, the kind of method developed by Annette Michelson in her essay "Toward Snow", Artforum 9/10 (June, 1971), p. 30-37. I am looking at these works through Merleau-Ponty's existential philosophy, whereas Michelson took a Husserlian, transcendental approach that would not vary according to the subject's position. 
understand affect through a phenomenological method that opens up other realms of multi-sensory experientiality and specifically, that involves the realm of the body and not just the mind. I wish then to consider cognitive processes as an important component that is only part of this kind of experientiality, and not necessarily central to the viewing of fringe works, as Peterson claims.

This chapter will focus heavily on describing seven categories -- aggressive, amusing, bodily, intellectual, meditative, monotonous, and sublime - that I have constructed based on surveying my own experiences of Canadian experimental media during the writing of this project. The categories were prompted by my desire to loosely classify my experience of audio-visual artworks in a way that is not consciously ordered and that bears, in my estimation, a more direct correlation to the actual qualities of the works themselves than a more explicitly semiotic or cognitive approach would. That being said, what first comes to mind when looking at this system of categorization is the apparent "oddness" of its design. Having no explicit intent from the outset, I tried to take a rather open, laissez-faire approach to letting the selections of thirty years of Canadian experimental film and video do to me what they wanted to do. In this sense, I was downplaying (quite actively) more rational and contextualizing approaches to experiencing cinema as a semiotic or cognitive system that imparts discernible knowledge and meaning to the spectator, in favour of a more exploratory pursuit.

Much later in my research I was introduced to an interesting passage in Michel Foucault's book The Order of Things: An Archaeology of the Senses that details an excerpt from Borges, wherein Borges in turn describes the strangeness of an ancient Chinese encyclopedia's way of categorizing animals. It seems that said encyclopedia shows how, at that historical time, animals were divided into disparate, seemingly unrelated categories, namely: belonging to the Emperor, embalmed, tame, sucking pigs, fabulous, frenzied, inmumerable, and having just broken the water pitcher, etc. 
In the wonderment of this taxonomy, the thing we apprehend in one great leap, the thing that, by means of the fable, is demonstrated as the exotic charm of another system of thought, is the limitation of our own, the stark impossibility of thinking that. But what is it impossible to think, and what kind of impossibility are we faced with here? ${ }^{5}$

Earlier I criticized Edward S. Small's assertion that experimental media, or what he at times calls "cinevideo", is always analyzable based on his model of eight generic characteristics that can be found in this kind of work. However, in light of Foucault's quote, I wish to state anew that my concern with Small's model is not based exclusively on any disagreements I might have about what eight qualities of fringe works are readily identifiable to all viewers, at all times, and in all places. Rather, my concern lies with how all rigid models of classification initiated from the experience of particular ephemera point to an impossibility or limitation (in Foucault's terms) of developing other means of ordering the phenomena of the world. In this sense, I came to (slowly) realize that part of the "use-value" of my seven affective categories lay in the complexities they produced by the arbitrary and subjective nature of their design.

Another Foucauldian concept, which Gilles Deleuze also picks up, is appropriate to introduce to this discussion, which is that of the "unthought". Just as the relationship of the body to thought is a complex one that is analogous to that of space to time, the body is intimately linked to the materiality of perception because it roots perception in the particularities of space and place.

The body is no longer the obstacle that separates thought from itself, that which it has to overcome to reach thinking. It is on the contrary that which it plunges into or must plunge into, in order to reach the unthought, that is life. Not that the body thinks, but,

${ }^{5}$ Michel Foucault, The Order of Things: An Archaeology of the Human Sciences (New York, NY: Vintage Books. 1970), p. xv. 
obstinate and stubborn, it forces us to think, and

forces us to think what is concealed from thought, life. ${ }^{6}$

Thus, the "unthought" invites us to be open to the inexpressible without forcing experience into strict outside categorization, as it is found in the body. Similarly, The Order of Things develops the idea that the outside is not a fixed limit but a moving matter animated by shifts and foldings that together make up an inside.

If thought comes from outside, and remains attached to the outside, how come the outside does not flood into the inside of thought, as the element that thought does not and cannot think of? The unthought is therefore not external to thought but lies at its very heart, as that impossibility of thinking which doubles or hollows out the inside. 7

In this regard, my system of affective categorization, much like the unthought which is present in thought, is "useful" inasmuch as it opens itself up to its own limits.

Moreover, I would argue that temporary sets of classifications can prove useful and do not have to be universal in their scope, unlike Aristotelian classifications of the world. Thus, my seven affective categories do not necessarily reflect the aesthetic and political concerns of the time in which certain films and videos were originally made, because some works may no longer be experienced in the way they were in other contexts. ${ }^{8}$ In a given period, experimental works correspond loosely to contemporary theoretical paradigms, be they transcendental phenomenology, structuralism, psychoanalytic feminism, semiotics, activism, queer theory, or identity politics to name but a few of the "trends" of the last thirty-plus years. In turn, even though these paradigms formed the original contexts in which fringe works were both produced and (affectively) received, these models are not necessarily always useful now, nor in

\footnotetext{
${ }^{6}$ Gilles Deleuze, Cinema 2: The Time-Image, trans. Hugh Tomlinson and Robert Galeta (Minneapolis, MN: University of Minnesota Press, 1989), p. 189.

${ }^{7}$ Gilles Deleuze, Eoucault, trans. Sean Hand (Minneapolis, MN: University of Minnesota Press, 1988), p. 97.

${ }^{8} \mathrm{I}$ will expand this point in the first section of my fourth chapter.
} 
keeping with $m y$ (or anyone else's) experiences of fringe work in the present. As I will explain, double articulation is what is responsible for these shifts in viewership contexts because each time a work is perceived, its expressions (though historically specific) are received anew. This observation came to me as I surveyed my interactions not only with older works, but also the more "current" works from the early to mid-1990s on. Generally speaking, their form and content did not seem so easily slotted in accordance with a prominent aesthetic associated with progressive discourses of resistance ${ }^{9}$.

The histories of our era are still being written, thus I find more loose, tentative assessments of phenomenological perception of audio-visual stimuli more in keeping with the contemporary situation. In fact, I want to suggest that affect and the categories it inspires shift in the chronological ebb and flow of Canadian experimental media production, in that the way to assess and define affect alters across time and space. For example, in the late 1970s a formalist approach to looking at Patricia Gruben's film The Central Character (1977) might have seen the film's black and white extreme close-ups of sweeping broom and pallid hands, or its use of negative printing for the image of a solitary woman, as a literalization of how the natural world can consume and blur the order apparent in the everyday. It would no doubt have been categorized as a "feminist" or a "formalist" film. Yet when I, a particular, intertwined body and mind who is embedded in the locatedness of the social, the political -- the "times", if you will - see The Central Character for the first time (as I did in June, 2000), what am I to experience and then classify as sensorially "important"? The same negative printing and detailed imagery still remain as essences of the film, and yet the way in which they function so as

${ }^{9}$ Gary Kibbins' essay "Flaming Creatures: New Tendencies in Canadian Video", in Lux: A Decade of Artists' Film and Video Steve Reinke and Tom Taylor, ed. (Toronto, ON: Pleasure Dome and YYZ Books, 2000), p. 48, substantiates my observation, as he notes how contemporary fringe video is not easily defined in terms of strict theoretial paradigms. 
to signify other phenomena -- social, cultural, conceptual, what have you -- has changed in terms of how I affectively make sense of those phenomena in the "now".

Thus, my seven affective means of categorization for fringe media both coincide with and diverge from strictly cognitive approaches, and indeed, from other paradigms that dominated particular periods of fringe media production. On the one hand, in certain works, affect is deployed so as to enable its audience to make sense of what the work is trying to do. ${ }^{10}$ Yet, on the other, I refuse to say that this is the only thing at work in the doubly-articulated relationship between the way the film perceives what it perceives, and the way we (the audience) perceive what it perceives. Affect occurs both in the expression of the work itself and in my reception of the work's expression. Moreover, the affective value of experimental media in general lies in these subjective qualities, as if it is relaying to the audience the message, "I do not want you to ever fully know me". Perhaps this, in turn, is where the pleasure of experiencing marginal media is derived, in that a work can never be truly known, but only experienced multi-sensorially through affective engagement with its form, aesthetics, and content. Nevertheless, my own embodied, social and political locatedness as a subject initiates a particular affective reception of the expression(s) of experimental media that, in turn, provides a valuable interpretive tool as to how to understand these works as (cultural) theory.

I will now proceed with defining each of the seven categories and describing certain emblematic works in accordance with Sobchack's notion of double articulation, which invites a type of viewership that oscillates between the subjective and the objective. This kind of film and video analysis via phenomenological double articulation involves three interrelated aspects, the first of which is that of perception by the work

\footnotetext{
${ }^{10}$ For example, I argue in the next chapter that by using the technique of superimposition, the experimental filmmaker Philip Hoffman initiates an affective response to his work so as to view his images as allegorical meditations on the constructed complexity of memory and history.
} 
itself and bears a resemblance to content or how a work is "about something". The second element involves the way the work expresses itself, to the extent that this can incorporate form and aesthetics, or the look and sound of the "thingness" of the work in its particularities. Last, and most importantly, is the reception by the viewer (me) and how s/he (I) receive that expression. Again, reception can imply a cognitive approach such as Peterson's, whereby the viewer makes an effort to assemble some kind of understanding or "knowledge" from her/his experience of the work. However, while my subjective analyses in the remainder of this chapter do at times touch on these kinds of experiences, my overall intent is to stress how affect in experimental media is perceived/received in the body of the socially and politically located spectator. ${ }^{11}$

\section{First Affective Category: Aggressive}

When I speak of aggression, I am referring to an intensity which is both sensory and intellectual. This is partly a function of the way a work expresses itself -- through its audio and image track(s) -- but it can also be about the relationship provoked between the subject matter and the audience. Symptoms of works in the aggressive category include, but are not limited to: a marked disjointedness between sound and visuals; manipulation and/or distortion of the image and audio track; politicized themes involving assaults on the subject; and the (ironic) challenging of societal authority. There are numerous examples of aggressive kinds of works found throughout the history of Canadian experimental production, from the earlier videos and films of Vancouver's Al Razutis to contemporary figures like Jubal Brown. I will focus on two works so as to describe the doubly articulated relationship that exists between what is formally and

\footnotetext{
${ }^{11}$ For the record, I self-identify as a male, underwaged activist and artist who is a third generation Anglo-Canadian of middle-upper class parentage. Then again, I also see myself as a Socialist trade unionist who is a guitar-playing citizen and participant in culture(s), both marginal and mainstream.
} 
aesthetically aggressive about these rigorous pieces and as a result, what makes them experienced as aggressing their audience.

Shawn Chapelle's Trans (1995) is a 5-minute, early digital video that begins with the off-screen sounds of explosions, whereas the image is, at the same time, a heavily mediated and pixillated transfer of colourful blurs created through post-production effects technology. The audience is immediately cued to be attentive, as the rumbling of the explosion (or is it an airplane engine?) precedes a random series of shots which, aesthetically, bear a resemblance to the kind of "smart bomb" images one would see in American coverage of the Gulf War. Titles soon appear at various intervals, displaying words such as: consume, incinerate, speed, Icarus. Phenomenologically the work generates in the viewer a range of emotional and bodily responses such as dread and anxiety, though this seems to be achieved as much through the interrelated design of Trans' image and sound tracks as through their separate character, as the pattern of what will be seen and heard at each consecutive moment is not predictable.

The experience of Trans is one of submission, in that its hyper-closeups in tandem with its abrasive disjointed soundtrack oblige the viewer to endure the work. This is not to say the work is unpleasurable, as the interplay between how the work perceives its subject (the signifiers of military power and their fetishization in the mass media) and expresses itself is intriguing. However, viewing (and listening to) the piece proves an act of endurance; though it is short in duration, the spectator must at some point "give in" to the rapid, incessant screeching of machines and engines and accept that Chapelle has chosen not to allow his plundered images to be seen in any kind of totality. Thus, the tape functions as a bodily assault, though its means of expression generate a "meaningful" experience, provided one is able to roll with how it is signifying and forestall the will to make sense of the work in more conventional ways.

On the other hand, Istvan Kantor's Jericho (1991) is aggressive to the extent that it uses scrolling text, off-key anthems, and iconic images as affect in order to generate 
visceral responses from the viewer. Kantor, who also produces fringe works under the names Amen! and Monty Cantsin, structures his video with eight discernible sections, though the logic of their linear organization is completely arbitrary as each of them is motivated by excerpts from the fictive journals of an "unproven" political exile named Joe Shoe. While elements of camp and parody predominate (as evidenced by the "dated" animation of jail cells and weaponry), the tape is also assaultive inasmuch as it perceives its subject (social alienation and the political disorganization of the Western world) through expressions which implicate the perceiver in the design of such a tyrannical reality. The use of the refrain "Get the fuck out!" abounds, not to mention the narrator's constant screamed assertion "I have nothing to say, but still I have a gun! I have a right to speak!", which obliges the perceiving subject to receive these expressions within the specificity of her/his socio-political situatedness. A significant part of Jericho's "aggressiveness" is the way its form and aesthetics attack the viewer's presumed political position, whether or not you "agree" with its (ironic) politics. It assumes an adversarial relationship with you, whoever "you" are.

The video also incorporates elements of performance which, specifically, involve the visual motif of a figure in prison stripes who carries a megaphone at all times as his dancing image is superimposed over multiple collage images of political rallies and industrial factories. Often this figure is seen in the foreground shouting slogans and rhetoric, as if he is (metaphorically) "in the face of "the spectator. This representation of the Other (activist, anarchist, artist, etc.) literalizes the kinds of aggressive expressions the work is making formally and aesthetically, to the extent that it initiates bodily and cognitive receptions which are particularly resonant. It is as if there are moments where we are obliged to cringe and wait, though this is only because Kantor's video is discursively designed so as not to provide its experiencer with any other ways "out". Thus, the affective experience of Jericho's subject(s) and the strategies which render it 
visible/audible prompt numerous responses (frustration, laughter, contemplation, anxiety) throughout its 17 -minute length.

\section{Second Affective Category: Amusing}

The works which I have classified as amusing express their "funniness" to varying degrees. This category does incorporate works which are explicitly humourous, though I have selected the two pieces I will discuss below because of how they are amusing in terms of ironic intertextuality and double articulation. This is to say that, as works, they not only perceive subjects which are somewhat askew, but express them in such a way that the phenomena of how they express themselves can also be received as off-kilter. Symptoms of these works include: irony conveyed through voice and music; an associative montage that explores the images' implicit meanings; ephemera which move the spectator to shift between laughing/crying, believing/doubting, wondering/fearing; and aspects of interplay between the literal and the metaphorical. A dictionary definition of the word "amusing" cites how it simultaneously denotes something that is both "entertaining" and "diverting", which is interesting in the sense that most works in this category oscillate between being perceived as overtly humorous and strangely sober or serious. In sum, an amusing phenomenological articulation cannot help but be culturally specific as it must depend on conventions of embodied response that play with the expected but in the process, alter those conventions and expectations.

For example, Susan C. Rynard's tape The Day Jesus Melted (1999) is a deceptively simple tale of a young girl's fall from grace. It perceives, as its subject, the narrator's childhood story of "the day Jesus melted", though the viewer learns midway through the 3-minute work that in this instance the literal (or iconic?) Jesus is a small, glow-in-the-dark figurine. The viewer receives the expressions of sweetness and innocence associated with her tale both through listening to the tone of the narrator's voice and, relatedly, seeing Rynard's pastoral, soft-focus images of a well-manicured 
lawn featuring a dollhouse that is shot as if it is to be perceived as life-size. The video's expressions are also organized in conjunction with the protagonist's outlook on the world, as the tape begins with her assertion "When I was a small person the world made sense. It had an order and a form." Similarly, her observation that "Sundays were for church" is accompanied by an image of a church, just as an earlier image of a schoolhouse is sutured to the statement "Weekdays were for school". Thus, the video's form expresses the discernment of totality, wherein reality is subject to a sensical order, although it is linked subjectively to the narrator/character of the young girl. In turn, the spectator receives these ephemera phenomenologically in such a way as to construct their own understanding of the form of that world.

However, the whimsy and amusement of childhood "totality" generated by Rynard's visual world is altered at the instance that Jesus is destroyed due to a tragic game of "rock star", wherein the figurine melts under the "stage lights" during the girl's playtime involving a misplaced light bulb. We learn, through voice-over, that this action caused the girl to stomp on the Jesus toy "until time split in two", thus creating a rupture both in the subject that is her life's narrative (the belief system that orders her existence was called into question) and the subject/object that is the video (this rupture alters the thingness/the appearance of the work). Just as she learns that "You can't bring bandagedup bodies back to life and you can't use one fish to feed thousands", the reality of her world, as it is expressed to us visually, turns upside down. This is literally expressed in a shot wherein the earlier image of the white dollhouse is inverted, which is received as a metaphor for how the perception of the world is rendered different once the means by which we experience reality are called into question. The video is received as amusing to the extent that it is folly (in terms of how it invites us to share her childish dismay at the disjunction between perception and expression), though when experienced as metaphor or allegory, it offers much to be unpacked. 
John Watt's Nuclear Breakdown (1984) expressed its perceived subject of the impending nuclear holocaust via the conventions of the commodified music video. Though its form, content, and aesthetics are informed by the temporal and cultural specificity of the mid-1980s MTV breakdance craze, its affective expressions are perceivable regardless of the time in which it is viewed. That being said, my understanding of its affective qualities (the hip hop soundtrack complete with record scratching, the images of Black breakdancers with the CN Tower in the background, the screenshots from long-since-antiquated video arcade games) is rooted in the specificity of the "now". Therefore, while this vantage point could allow me to receive the work as "dated" based on nostalgia alone, I am nevertheless aware that the video was structured so as to be (originally) seen as heavily ironic. Watt formally accomplishes this through the aesthetics of video toaster montage which he uses to juxtapose images of urban youth playing in the street with stock footage of mushroom clouds, or images of fireballs that dissolve into people dancing on an outdoor basketball court. The viewer perceives these images as amusing (in a dark-comic kind of way) due to their relationship to the work's audible qualities, for the video's conflicted, oft-violent images are glossed over with a rap about the "nuclear breakdown" that is fast approaching society. The pun, of course, is intended, just as the language and diction of the rap expresses that the work is to be received as humourous. Nuclear Breakdown is "funny" in how the viewing subject shares its ironic expression of its perception, though I also experienced amusement because of the disjunction in experiencing the affect of early hip hop and breakdance culture, which is generated in hindsight.

\section{Third Affective Category: Bodily}

All works of film and video are "bodily" in the sense that our perceptual interrelationship with the cinema involves sensory interactions that invite the works into our bodies, and vice versa. However, in this context, the bodily category is meant to not only 
incorporate fringe works that are especially affective in terms of how they register in our bodies, but also describes media which are expressed and received as especially physical. Symptoms of the works in this category include: an emphasis on the performance of the body; the use of absences to convey what is said in the audio text or conveyed through image alone; narratives that are especially "personal" in their subject; and an emphasis on bodily movement and emotion. Thus, as works, these films and videos perceive the body and express it in such a way as to inscribe self-reflexive bodily responses in the viewer that call attention to the limits of corporeal being.

Norman Cohn's tape In my end is my beginning, Part Two: Lucy Brown (1982) is a document of an elderly woman living out her final days in a Prince Edward Island nursing home, though what is most significant about how the video expresses itself is ascertained through an organized style and form informed by the conventions of the observational documentary. Cohn's tape is bodily inasmuch as (in every scene) his camera subjects the figure of the aged and bewildered Lucy Brown to an incredible degree of visual scrutiny. In fact, he deploys the aesthetic of the extreme close-up throughout much of the piece which, although it runs in excess of 35 minutes in length, only comprises a few scenes. Because of the lengthiness of each vignette, which "detail" the daily rituals that regulate Lucy's body as performed during recreation hour or before bedtime, this expression is meant to be received in the body as with a shared feeling of duration. Often times there are long moments in which there is neither dialogue nor action, as if we are being obliged to concentrate on the stark details of her wrinkles or her thinning, greying hair. The experience of Cohn's video is also one of regulation, as it is "about" how, in the context of the nursing home, the experience of the body is mediated by the conflicting forces of ageing and the caregivers who wish to slow its advancement. Second, what the tape expresses is also regulated given Cohn's voyeuristic camera and choice not to trim extended scenes, which gives the viewer an unsettling feeling of intimacy, of over-closeness, registered in the body. 
While Cohn's audio-visual strategy does emphasize the supposed monotony of Lucy's existence, it was not received (by me) as boring because I found his camera's attention to detail (and his editorial choices of what to detail) intriguing. Perhaps the most "bodily" experience in the film involves a scene in which an orderly feeds Lucy her dinner. The representation of the ritual of eating as a means of sustenance has multiple meanings in this context, for Cohn's long take of Lucy moaning, struggling to finish her meal, precipitates an affective response, whereby our bodies feel a range of emotions from pity/awe at the image of Lucy eating, to hunger for/aversion to food, to name but a few possible receptions. Furthermore, the scene of Lucy in the activity room is particularly painful to watch as the camera obliges the viewer to focus on her face, whose eyes seem unable to focus on the orderly asking her to repeat what day the calendar says it is. In watching this video, the perceiving body and mind register Lucy's body's struggle to endure the passage of time as it is subjected to incessant routinization.

Sisi Penaloza's Thumper (2000) is a 6-minute performance video that involves the artist's manipulation of a home-made horse massager from the early 20 th century and perceives her bodily interactions with this loud, unwieldy device as she navigates the vibrator over top of the men's briefs she is wearing. Penaloza's handheld camera details this interplay between the flesh and the machine, though often the image loses its focus in the camcorder's attempt to adjust to the details of the vibrating bulbs on the base of the vibrator. This expression of perception is a particularly embodied one, in that the spectator's ability to "concentrate" (in a conventional sense) is being challenged by the limitations of the image/camera's "thingness", its inability to focus. The quality of the image recalls the scene in Steele's Facing South where she comments "It is difficult to see closely down here." There are but a few different shots in the piece, though one later on is in extreme close-up, so as to express the machine's movement between her legs and the details of the pubic hair that emerges from beneath her underwear. This work is bodily in that it is perceived, expressed, and received as such; the early images (which 
appear to show a woman masturbating) give way to a sustained image that is not exactly pleasurable. For instance, the vicious roar of the massager's motor is heard qualitatively as "source sound" and it is loud to the extent that it overwhelms (or mutes?) any sounds of pleasure that can slightly be heard which one might connote with the female orgasm. Furthermore the interplay between the machine, the body, and the sexual is complicated by a rock and roll soundtrack that builds to the chorus "All I wanted was to be a happy man", which re-writes this female body as multiple. The tape's visceral aesthetics and content roots the artist's audio-visual articulation of the machine-flesh in our own experience, thus the reception of these expressions in Penaloza's Thumper must be described as particularly embodied.

\section{Fourth Affective Category: Intellectual}

All experimental works are intelligent subject/objects, but what are the qualities of a film and video that allow it to be best described as "intellectual"? Of my seven categories this is the one which focuses most clearly on cognitive processes as a significant part of the cinematic experience, though my intent here is not to declare this activity as more valuable than any other. Rather, I wish to point out that intellectual fringe works express themselves so as to be experienced intelligently by the engaged spectator. One quality of intellectual fringe work is sometimes you think "I could just read this", as it puts a great emphasis on language. Other symptoms of these works include: the privileging of the human voice to convey information; abstract associations between text/sound/image; wordy sequences that are discontinuous with the information in the image; and formal structures that are conceptual or associational in their design.

Doug Porter's Losing Sleep (1996) is an essayistic video that perceives the subject of insomnia and expresses it structurally in a manner which is contemplative, and is received as such. Its 14 minutes are comprised mainly of an interview with a verbose computer programmer/hacker dressed in black who waxes poetic on the nature of 
consciousness and how he is currently having difficulty sleeping. His choice of words display a strange fascination with incessant mathematical calculations and invites the imagination of non-sensical images such as seeing television as a "visual data storm without a recognizable form" and computers as "replicating a super-sensorial razor-blade burn". While Porter does privilege the spoken word as a means of conveying "sensible" information, he allows the interviewee's face to be seen for most of the piece, usually visible only as a small black and white image within a larger frame. The images that comprise the larger frame appear in slow motion, are somewhat grainy, and often depict the same man as he walks the deserted city streets at night. This not only provides a visual context for the subject the man is discussing, but functions expressively so as to initiate a response in the spectator wherein the affect of the slow-moving, ghost-like figure lulls them into a viewership position that makes them receptive to his complex philosophical concepts. However, the tone of the hacker's voice works as counterpoint in this regard, for it represents the work's most kinetic quality in that he sounds overstimulated, as if he has drunk way too much coffee. Thus, an affective tension is established between one's ability to concentrate enough in order to hear (and understand) what he is saying, and not concentrating enough so that the "unthought" implicit in the relationship between those words and the visuals comes forward. The jagged, rambling quality of his speech is what makes this tension experienced in the body. 12

\section{Fifth Affective Category: Meditative}

To meditate means to engage in continuous and contemplative thought, to cogitate, or to ponder; thus, these kinds of works not only incorporate affective qualities that generate this kind of experience, but bear aesthetic and formal attributes that can be

\footnotetext{
${ }^{12}$ Two other examples of "intellectual" fringe works appear in other discussions in this thesis. They include Mike Hoolboom's White Museum (1986) in Chapter 1 and Gary Kibbins' The Alien Seaman (1998) in Chapter 3.
} 
described as seeming meditative. Symptoms of these kinds of works include: the recurring use of particular images and sounds, often in the form of a loop; an emphasis on silence or the non-verbal which effaces the invasion of the "all-knowing" spectator; elements of performativity and ritual; and the enaction of editing patterns which are strategically rhythmic and temporal. Regardless of the works' specific themes and/or content, meditative works are so inasmuch as they work the viewer into a passive (though, not submissive) position that is open to audio-visual stimuli. What meditative works perceive is less important than how they express.

John Greyson's Pack'n (2001) is a meditative work that initiates a range of emotional responses, including that of amusement and even nausea. Formally, the fourminute tape is a vertical roll of images the artist shot while participating in the April, 2001 protests against the Free Trade Area of the Americas Agreement (FTAA) in Quebec City. However, Greyson's camera does not focus its attention on more conventional sites of the political rally (marching crowds, rousing speech-makers, etc.). He chooses instead to target the crotches (literally) of the police officers whose job is to expose the protestors for arrest. The montage juxtaposes crotch with crotch, followed at times by images of street activism and violent police action, though the pacing of how the images "roll" from the bottom to the top of the screen as a kind of incessant vertical wipe, generates a bodily response of hypnotism. It is through this affective response that the viewer is able to receive the multiple meanings of Greyson's associational montage. The video can be seen as a meditation on the interrelatedness of state power, oppression, and patriarchy, though the use of humourous intertitles and images of "world leaders' crotches" provide a comic touch that make this lesson in surveillance and control palpable somehow. Strangely, Pack'n experiments with form so as to destabilize the phallus as a site of violence and aggression in order to render it, within the systemic logic of the vertical roll, a site for contemplation. 
In a different sense, Zachery Longboy's the stone show (1999) is also meditative, though in a more nuanced way. The tape documents an interview with the artist's mother, who recalls the memory of her late mother and her relationship with the natural and social realms of her Native community. The narrative is one of longing to reconnect with a fallen woman who "was comfortable in nature", though not quite at home within the rituals of the West such as Hallowe'en. The casual beat and singing associated with the music of Longboy's Sayasi Dene culture is received (from the background) as a lulling kind of effect; the listener is drawn into the sing-song's calming rhythm and intonation. Longboy's screen comprises multiple image-surfaces (of earth, family photographs, hand-drawn maps, furs, and writings) that appear without order against iconic images of running water and grass. These images not only connote the narrative's "Othernesss" with respect to its relationship to a centre, but also caress the visual senses, as the moderate pacing of when they appear to the eye is ordered so as to not confuse the viewer. Thus, the effect of the music in conjunction with the images service a contemplative mode that invites meditation. In this context his mother's statement "I wish I had listened to some of her stories" is received on multiple levels, though if sutured to the "knowledge" conveyed by the images of a disappearing culture, it can be taken allegorically so as to meditate on the finiteness of experience and the lack generated when certain things (and beings) come to pass.

\section{Sixth Affective Category: Monotonous}

Experimental works which are experienced as monotonous are often conceptual pieces that are minimalist in their formal and aesthetic design. Curiously, my responses to a lot of 70 s video for example could categorize them as "monotonous", though I must acknowledge that the theoretical paradigms which surrounded the production of those tapes encouraged a kind of video art practice that was conceptual, allowing most of the work to appear sparse. Symptoms of these kinds of work include: the minimal use of 
sound; little manipulation of the image through editing or other post-production effects; static shots. I do not wish the term monotonous to imply "boredom", as often the simplicity of this kind of works' expression initiates a level of concentration in the viewer that makes the piece's reception all the more satisfying. In this regard, sparseness can be seen as focusing bodily and cognitive responses on a work, which is not entirely bad, in that it stresses how the relationship between expression and reception is most important. True/False (1972) is an early video by the late Colin Campbell that takes, as cue for its structure, a series of spoken assertions which are falsifiable. The tape opens with a blank screen and the artist's claim (in voiceover) "I like Sackville. True. False.", eventually the subject enters the frame and looks off-screen to the left. In the subsequent 15 minutes Campbell performs a series of utterances "of a very 'personal' nature" that indicate how identity is difficultly realized in the social constructiveness of language, for every claim that he smokes pot, or has crabs, or is Jewish, or has attempted suicide, is stated as being (both? either?) true/false. The video camera, which never changes position, nor cuts to a different shot, takes on the position of the interrogator, as Campbell's eyes slowly explore the off-screen space before coming to rest directly on the surveying lens when he states "Colin is my real name. True. False." The deadpan expression in both his voice and facial expression(s) engender a concentrated response, though experiencing the work in its entirety is received as (intended) monotonous.

Kika Thorne's Intraduction (1998) is essentially a reading of Freud's theory on sexuality. The tape opens with a blood red screen while audio noise, pinched from the ouevre of the "no wave" band Sonic Youth, is heard in the distant background, and soon the image of a woman reading in German from a book fades into the frame. Upon finishing the passage she is asked to translate it on the spot, so she speaks of how Freud's text describes that sexuality begins after birth and how it is necessary to distinguish between the sexual (behaviour) and the genital (biology). The video's comment on languages expresses a conceptual link in terms of what the woman, based on her aptitude 
as a translator, is able to describe about the text and what Freud's writings intend to say about sexuality and behaviour, though that is about all that is going on. The effect of its monotony on me was such that it generated a desire for more stimuli, of any kind, as I received the way the video expresses its (lack of?) perception as limiting.

\section{Seventh Affective Category: Sublime}

The sublime can be described as characterized by elevation, inspiring awe and deep emotion, though the Romantic definition of the term sees it as something which is beautiful because it is terrible, as if to get through terrible experience is to describe something great. Symptoms of the works in this category include: subject matter that is difficult to comprehend, such as death, love, or consciousness; a strong emphasis on the look of the piece and its aesthetic appearance as it relates to the beauty/terrible interplay; experimentation with the image's colour, tone, and speed; image and sound tracks layered. with multiple sources. The indescribable or imperceptible qualities of sublime works' subject matter give a strangely "inexpressive" quality to their expression(s). Thus, affective responses to sublime works generate the feeling of being overwhelmed, of being subsumed by their form and content, inasmuch as the senses are simultaneously stimulated and unsettled.

The aesthetic lushness of Barbara Sternberg's Like a Dream That Vanishes (2000) gives the work its sublime quality, as its expressions are received in a manner that consumes the senses. The film, which shares both a stylistic and thematic kinship with the sensorially-dense works of her peers Philip Hoffman's What These Ashes Wanted (2001) and Gary Popovich's Archaeology of Memory (1993), is "about" death. Similarly, its expressions approach this subject from a vantage point that presumes to "know" very little about its subject, thus they are audio-visual experiments with the representation of mortality and/or existence. There are numerous extended sequences in which Sternberg's image and sound tracks are blurs - of noise, of colour, of texture, of iconography - and 
it is through experiencing these "filmic" qualities of the work that I received its various optical prints and scratches as bodily. These passages are periodically broken up by sections of an interview with an elderly, terminally-ill philosophy professor whose "function" is to literally articulate some of the questions the work's expressions are inviting us consider, such as "what might death look (or feel) like?" Similarly, the viewer is overwhelmed by this interplay between the expressed (the affective qualities of the sound and image) and the unknown they are intended to relate, which is the subject of death. While Like a Dream That Vanishes could also be categorized as "meditative" or "bodily", it is (in this context) most usefully defined in terms of the sublime because of the received tensions its inexpressiveness induces.

Paula Levine's Mirror, Mirror (1987) is also an example of a sublime work, though on a smaller level. The video uses only one image, though it is slightly blurry and slowed to the point that each of the male subject's movements is accentuated and drawn out. The image is that of a masculine, "beefcake" kind of guy on a beach who slowly turns toward the camera, unaware that he is being surveyed from across the surf and sand. The soundtrack is layered and comprises women's voices in hushed conversation, though what they are saying is barely audible because of Levine's choice to decrease the speed and volume of their playback. Slowly the man's face appears to acknowledge the camera's presence as, much like the work's title suggests, I received his image as a reflection of the awareness that his maleness, his "beauty", is being subjected to a voyeuristic gaze that is somewhat punishing and disturbing. While this interplay might be understood cognitively as an inversion of the look of the classical cinema, affectively we are unable to make finite sense because the image eventually freezes on his bare, muscled chest. The video, though under three minutes long, is overwhelming in the sense that it is most interested in expressing itself in a manner wherein the viewer's reception is one of feeling unsettled. 


\section{Summary}

Each of the aforementioned seven affective categories has a distinctly articulated relationship between perception, expression, and reception, often placing more emphasis on one than the other. For example, it is apparent that works in the intellectual category emphasize their perception more than, say, works in the sublime category, which are expression-heavy, or works in the meditative category, which emphasize reception. Sobchack's phenomenological model of double articulation opens up different kinds of theory each piece is capable of, inasmuch as the ways that some perceive best, some express best, and some are received best draw attention to disjunctions between the various articulations. Thus, each category is "smart" in its own way and what pulls their meaning together is the viewer's subjective response, which in this case is my own. In the next chapter I will look more specifically at some of the ways fringe media are indeed works of cultural theory, therefore the preceding categories and how they are constructed contextually can be seen as a model for the how - how fringe media do theory. While I will still be describing each work phenomenologically in the next chapter, my argument(s) will emphasize the what -- what is the kind of (cultural) theory that emerges when we experience fringe media affectively and furthermore, what is "useful" about it? 


\section{Chapter Three: Experimental Media as (Cultural) Theory}

Perhaps the fringe moving image artist is best characterized as one who makes the relationship between her/his works and the viewer as "open" as possible. It is this defining relationship of experimental media production in Canada that I wish to pursue in this chapter, as opposed to considering strictly institutional or formal assessments of the field. Therefore, it is important to restate my critical emphasis on writing about the works in a way that continues them into the viewer's socially and politically located body, rather than simply contain them as texts, out there, to be analyzed in the service of wholeness. Furthermore, this way of experiencing experimental media allows for a way of seeing and hearing these videos and films as works of (cultural) theory.

Let us revisit then the affective means by which Canadian fringe moving image works represent, challenge, or re-configure fixed notions of how national or personal identity is constructed. As I argued in Chapter 1, marginality is a defining aspect of Canadian cinema in general. Here I wish to argue that fringe or experimental films and videos take advantage of this marginality as works of audio-visual theory that can explain cultural phenomena. Thus, the requisite object/subjects of study here are the rarely viewed, oft-forgotten, difficultly read audio-visual expressions of peoples who stand precariously as marginalized. ${ }^{1}$ To this end, there is a loosely documented history of works both in this country and abroad which challenge the dominant ideologies that institute the marginalization -- or what I'll call the "fringe-ing" -- of the discursively constructed identities to which I refer. I see, currently, a shift away from conventional understandings of the margins of film production as only a reaction to the centre in order to try to examine the fringe in its own regard.

\footnotetext{
${ }^{1}$ Again, the question of how these film and videomakers are marginalized is a complex one. In this context I wish to assert that it is not so much the individuals themselves (in terms of identity politics) who are marginalized, but more that the certain ways they inhabit history and political agency makes a virtue of marginality.
} 
In this respect it is helpful to recognize, drawing from John Champagne's The Ethics of Marginality (1995), that in the modern period in the West culturally marginalized peoples are not simply denied subjectivity. They are, rather, granted a limited and specific subjectivity which renders them useful in relation to a dominant culture. Specifically, this construction of the contained Other functions as an oppositional term for the formation of a normalized subjectivity.

The relationship between normalized and Other cannot, however, be one of absolute opposition, for such an opposition would render the Other 'beyond' use, as it were: too abject, too radically heterogeneous to be set in relation - even a relation of opposition - to the normalized. ${ }^{2}$

His assumption is that no relation whatsoever is possible between marginalized and center -- or, between "fringe" and "mainstream" - if the margin does not contain something of the center, and vice versa. "In other words, in order to function as its opposite, the Other must present what is lacking in the normal, a lack that, paradoxically, must have been present at the outset in the normal."3 Therefore, occupying the place of the Other permits an ethical understanding which is not so much an identity but a stance, that makes it possible to engage in non-linear readings and constructions of History.

By my estimation the fringe artist working in the mediums of film and video has grown out of functioning simply as an opposite to the dominant, teleological mode of producing images in the service of constructing firm understandings of socially produced identities. ${ }^{4}$ Any cursory survey of the body of fringe works produced in this country

\footnotetext{
${ }^{2}$ John Champagne, The Ethics of Marginality: A New Approach to Gay Studies (Minneapolis, MN: University of Minnesota Press, 1995), p. xxv. ${ }^{3}$ Ibid, p. xxvi.

${ }^{4}$ While she focuses primarily on the work of American artists, Patricia Mellencamp exhaustively documents what preceded these kinds of changes when postmodernism dominated fringe practice and criticism throughout the 1980s. See Indiscretions: AvantGarde Film, Video \& Feminism, (Bloomington, IN: Indiana University Press, 1990).
} 
observes notable formal and thematic changes in the ways the marginalized fringe artist, as cultural producer, approaches the organization of images and sounds so as to construct open meanings that are not simply oppositional or reactive, but "productive". Steve Reinke's compilation The 100 Videos (1990-95) provides an interesting marker for this shifting tendency, as most of the artist's tapes in the series are merely dubbed from other mainstream image sources (B movies, junk TV, skin flicks) and edited so as to provide a backdrop for his deadpan, ironic lamentations as narrator. In Chapter 1 I noted how Canadian artists use ironic intertextuality in order to assert their marginal cultural identity, however it would appear that videos such as Reinke's demonstrate how artists are moving beyond the deployment of irony as a discursive tool. For example, while his mass media images betray their origins in that they are visually discernible as having been produced in order to stimulate profit and desire, their conceptual re-arrangement, in conjunction with Reinke's spoken (and sometimes written) words, generates the effect that their meaning is not just being critiqued, but altered somehow. Reinke appears simultaneously to fetishize, deplore, adore, and mock the mass media's spectacular images, so as to not quite oppose (in a rigid sense) the conservative politics at work therein, but in order to use video as cultural detournement that exposes subversive meanings which lie dormant in the faces of cultural figures of varying notoriety, such as Oprah or gay male porn actors. The videos enact form and aesthetics so as to reveal the Other in the normal, or in Foucauldian terms, the "unthought" in thought. The 100 Videos and other works of its time like Jan Peacock's WHITEWASH (1990) and Doug Porter's I'd Like to Move On If I Could Please (1990), signal a move by artists away from making experimental media productions which are strictly oppositional, moving instead towards making works which are deceptively more complex and less easily cognizable.

What I am suggesting is that within the recent histories of Canadian experimental film and video there has emerged a renewed engagement with the prospect of developing an audio-visual expression that does not function primarily so as to critique mainstream 
culture and dominant ideology. Rather, these works are moving beyond identity construction in order to produce visual and audio cultural theory from the problems of identity. The videos and films I will deal with in this chapter continue to formally allude to what is "lacking in the normal" (read, the mainstream) as that which may have been present from the outset. But what seems "new" is that it is not strictly the intention of these artists to valourize their culturally marginalized positions, to point out problems with the dominant language of power and "go home", if you will. Instead, as I will explain, works such as Gary Kibbins' The Alien Seaman (1998), Mike Hoolboom and Steve Sanguedolce's (1992), Philip Hoffman's Kitchener-Berlin (1990), Steve Reinke's Afternoon: March 22, 1999 (1999) and Kika Thorne's Work (1999) can be read as markers of a transition within the broader discourse of marginal, experimental works. These films and videos move away from the mere critique of encoded, dominant cinematic ideologies and shift towards a newer understanding of the marginalized as not strictly opposite to the mainstream, but capable of theoretical work that is productive: in particular, the work of epistemology and history. Furthermore, I will explore two formal means by which these theories are developed: through voiceover narration that is disjunctive with images (as in The Alien Seaman and and the layering of images through the technique of superimposition (as in Kitchener-Berlin). I conclude this chapter with a discussion of two recent works that approach the representation of artists' labour and how they reflect upon the very possibility that art can be meaningful work.

It would appear this transition coincides with broader cultural responses to the Other, as articulated by Champagne, which understands the site of marginality of the Other as a potential avenue to new modes of thinking, though I don't think the transition is necessarily determined by these cultural responses. Fringe artists do not (necessarily) seek to extend a greater subjectivity to the Other, but attempt to make a resistant and transgressive use of the very lack in and through which the Other is constituted. Though as Sean Cubitt suggests in his study Digital Aesthetics, the position of resistance, which 
effectively defines an Other that is ultimately "needed" so as to define the self, is no longer useful in the age of all-encompassing global capitalism because resistance is always incorporated into the ideology of the centre. ${ }^{5}$ Therefore, what must be sought is an autonomous and pro-active position for political agency in art that permits thinking the new and the open. In this respect, Champagne argues that the Other embodies a productive response to the normal and that criticism affiliated with this position might work to render such a relationship ethically and politically useful.

To this end, I will call for what I will provisionally and strategically name an 'ethical criticism', a criticism ethically committed to altering the existing relations of power so that they might become more fluid and easily reversible. ${ }^{6}$ (xxviii)

\section{Experimentalism and the "Reversal" of History}

Recent Canadian fringe audio-visual works suggest that historicized cause/effect connections may not be as strong as they once seemed to appear. Furthermore, these causal chains, which suture dominant teleological modes of thought to place and/or event, may very well shift in conceptual space just as easily as s/be who is acting as cultural surveyor might move through the "real" world. How then might this re-thinking of "our" histories, our experience of the body's passage through physical space, be accomplished? While mainstream cinema often tends to both linearize history and incorporate any resistance, fringe media propose other historiographies that are difficult to consume. It is for this reason that these films and videos can be seen as works of direct theory. Their positioning on the fringes of culture and the marginality which informs their making and reception allows them to appear as sensuously experienced expressions of culture.

${ }^{5}$ Sean Cubitt, Digital Aesthetics (London, UK: Sage Publications, 1998), p. xi. ${ }^{6}$ Champagne, p. xxviii. 
Fringe media can be epistemological, exploring new ways to understand how we know. This theoretical work often involves the technique of rupturing the conventional logic of how image is sutured to sound. This brings the discussion to Gary Kibbins' 1998 film The Alien Seaman, which not coincidentally, involves a narrative grounded on the interesting possibility that history, and by proxy, our means of constructing ideas about the past in order to understand ourselves, can be blown inside out. The work begins with an address by a male narrator with a Maritime accent who, while off-screen throughout the twenty-minute film, does appear to reveal his identity somewhat by identifying body parts seen in reclaimed autopsy footage as (potentially) his own. In fact, the first shot incorporates archival footage of a coroner examining a dismembered human leg, alongside which the voice of Kibbins' narrator proclaims it to be "the first leg of the journey". For you see, from beyond the dead come the oral musings of this "alien seaman", a perhaps fictive, ever-nameless Maritimer who, having died in the Halifax explosion of 1917 , returns conceptually speaking, with the message that perhaps going back in time to prevent cataclysmic, historicized events from ever happening is not such a difficult proposition.

There is a sequence later in Kibbins' intellectual film which probes the idea that the only way to understand history is to reverse the means by which we construct it. That is to say, the only way is to unwind the dominant ideologies of logic and containment that narrativize the past, in order to reclaim or reveal previously indiscernible undercurrents of historical difference and alternate identities. This is conveyed quite provocatively in a narrated visual passage which follows documentary footage that celebrates the federal government's efficiency at "attaching names to know-how". In order to identify the disfigured bodies of the Halifax explosion, often the surveying coroner had to surgically turn the body inside out so as to identify its history because the initial blast had reversed its appearance. The narrator asserts that if this scientific procedure is so easily accepted culturally as "logical", then perhaps similar procedures 
could be carricd out on history itself, in order to re-consider the causal relations which supposedly render historical development rational. However, Kibbins' images are paradoxically fixed and still in juxtaposition to the lofty aspirations of the narrator. Most of the visuals in the film are black and white travelling long shots of a ship that is part of a nautical museum exhibit in Kingston, Ontario. In one "sequence", the viewer sees an unidentified male figure walk throughout the ship (the ghost from 1917? the narrator? a tourist?), as if he is looking for something that is never found, though the audience has already been cued to the knowledge that the ship is in fact in a dry-dock and immobile. Hence, there is a distinct rupture between the logic of the "historical" reality connoted by the images and the ability to reverse past and presentness conveyed in the narration.

Aexice's formal and aesthetic strategies perpetually confront and interrogate a viewership position which is grounded in the teleology of colonialism and socioeconomic progress. Numerous instances in this self-reflexive, experimental travelogue film situate a subjectivity wherein the question of what is cultural "advancement" is raised. For example, the sequence where the narrator asserts "[I] came to this country to erase everything left behind", just as the visuals cut from the Mayan ruins of Mexico to the downtown buildings of Toronto, is indicative of this strategy. I find this interesting with respect to the film's form and content, or its expression and percpetion, which at first glance, are inarguably placed within the cinematic history of ethnographic documentary filmmaking; hence the various audio-visual passages which highlight tourist sites and "exotic" activities such as bullfighting. What is intriguing, though, with respect to the question of reversing or inverting history, is how Hoolboom and Sanguedolce navigate/manipulate their filmic discourse so as to continually move outside the norm, which in this case involves the consumptive gaze of the Western tourist. For instance, in one intriguing sequence saturated images of rural Mexico are set against the words of Hoolboom's narration as he posits, "The light (here) obliterates. There is nothing left but the present, as opposed to Toronto, which calls attention to its history." 
This strategy points towards a historiography which is not so much about possession (about knowing and mastery) but about calling our own aspirations into question with every fleeting, fading glance.

These are two examples of Canadian experimental film and video that point towards the idea that there are histories which are on the fringe of the surveyable. Barely seen and heard, these subtle moments of human experience appear to slip away, degrading over time as the flow of cultural history is continually periodized as events and disseminated via limited and conventional means of thinking about the historical world. Thus, the bodies of Other histories which may not be inherently understood through forward-moving, linearly constructed methodologies, are active because they are rendered surveyable only as "alien", seen from the outside-in and thus, difficultly incorporated in Cubitt's terms. To borrow from the disembodied voice of the narrator of Kibbins' The Alien Seaman, the alternate-thinking surveyor might unravel the cause-andeffect relations which render meta-histories logical by "seeing in the dark" and, in so doing, move towards alternate conceptions of landscape and personal or collective memory. "The secret," as the film's narrator proposes, "is to stay in the realm of human agency. For the prospect of death wonderfully concentrates the mind." In the case of this film, as well as and other works that "reinvent" historiography such as Susan C. Rynard's What Wants To Be Spoken, What Remains To Be Said (1992) or Zachery Longboy's the stone show (1999), the implication is not that our histories are necessarily "dead" and/or "lost" to a past from which meaning can never be retrieved. These emerging, experimental Other (Canadian) histories, much like in Kibbins' metaphor of the alien autopsy, must be inverted in an attempt not only to make them sensuously recognizable, but in so doing, to serve potentially as an alternate conceptual means of non-totalizing historiography. 


\section{Multiplicities of Memory}

The Canadian Broadcasting Corporation marked the new millennium with the epic documentary series Canada: A People's History (Executive Producer Mark Starowicz, 2000), which as a production funded for the most part with government money, not only points to the network's tradition of enacting sounds and images so as to construct finite notions of the nation-state for its audience, but also implicitly addresses Canadians' on-going fascination with understanding our/themselves through a collective, totalizing sense of History (from on high). However, it could be argued that such productions serve as much to obscure or distance the viewer from any discernible sense of pastness, as they do to reveal any new modes of inquiry into the question of Canadian identity. ${ }^{7}$ Moreover, documentary productions such as this ambitious thirty-hour series privilege discernible narrative and dramatic tension in their "historical" re-enactments, as these episodes assert that by simply "telling history through the voices of those people who lived it," 8 pastness can be rendered "authentically" and made empirically accessible as cultural knowledge in the present.

This section will investigate how the fringe moving image artist in Canada enacts the mediums of film and video from the margins so as to contribute to discourses of how we remember or "know" ourselves in the present as a disparate nation of individuals. My argument is that certain experimental works do not merely examine themes of memory and history conceptually, but more interestingly, are organised so as to be affectively experienced by the viewer as cultural memory, in all of its fragments. In other words, fringe films and videos are works of historiography that ask how we can understand the past. Of particular importance here is the aesthetic strategy of layering multiple images

${ }^{7}$ am thinking here of the discursive function of suture with respect to narrative and its effect of "flattening" difference and alterity that I outlined in the first chapter. 8 This quote is made by series producer Starowicz in the film Making History (CBC, 2000), which documents the production of Canada: A People's History. 
one atop the other, which can be experienced as a visual allegory for the way identities are ever shifting between past and present tenses. I have chosen to concentrate on the technique of image layering from amongst the many formal devices that could be "historiographical" -- although visual and or/audio montage also come to mind -- because of the propensity of recent history-themed experimental media to make use of the device. ${ }^{9}$ I am inspired by William C. Wees' scholarship, which examines the dialectic between visuality and the technologies and techniques of the cinema. I wish to extend his thinking to consider how this interrelationship, which hinges on how one sees, also impacts the construction of memory and notions of pastness.

Techniques [such as super-imposition] 'pose questions about seeing' and confront the viewer with a more complex and dynamic experience of visual perception than is normally the case in film viewing. This suggests that the two lines of argument concerning what we are capable of seeing and what the apparatus is capable of showing might be described more accurately as two terms of a dialectical relationship between visual perception and the technology and techniques of cinema. 10

The formal technique of layering film or video images one atop the other - a visual effect accomplished either in the optical printing lab, through double exposure, or through digital editing - is curiously positioned as an aesthetic, and perhaps, allegorical device in the history of Canadian experimental film production. My understanding of allegory here is shaped by Judith Butler when she writes, "Allegory is in its most general

${ }^{9}$ I am thinking not only of other Hoffman works but also the stone show, another Longboy tape called Confirmation Of My Sins (1995), Shauna Beharry's Seeing Is Believing (1991), and Richard Fung's Sea In The Blood (2000), to name a few.

${ }^{10}$ William C. Wees, Light Moving in Time: Studies in the Visual Aesthetics of AvantGarde Film (Berkeley, CA: University of California Press, 1992), p. 4. I should note that Wees' methodology is similar to Sobchack's model of double articulation, which I expanded as a means of categorizing fringe media in Chapter 2, though his criticism is more concerned with dialectics. 
formulation a way of giving a narrative form to something which cannot be directly narrativized." 11 Because the experimental work bears witness to an image that is not entirely "readable" in the traditional sense, the sensory experience of the work is initially unsettling to a certain degree. For if what is experienced visually at the surface of the image is complicated by multiple layers of presences, then the prospect of "knowing", or at the very least, perceptually resolving what the image is/was meant to convey within larger frames of reference is further obscured. Processes of signification and sites of address are blurred, which is another way the sound/image form invites a certain kind of epistemology. It opens up avenues of inquiry for the viewer into the uneasy relationship between perception, film as perceived object, and how it is intended to be perceived.

I wish to recall Vivian Sobchack's assertion that the work of film has the capacity to signify -- to not only have sense, but also to make sense through a unique and systemic form of embodied communication. This point, the idea of cinema "making sense", is something I would like to examine in more detail here. Specifically, what kind of sense is made by fringe media makers who incorporate the technique of layering in multiple sound and image sources in their works? Sobchack writes that "Any film -- however abstract or 'structural-materialist' -- presupposes that it will be understood as signification, as conveying meaning beyond the brute material presence of light and shadow oin a plane surface, [for] the cinema assumes and assures its own intelligibility," even if it assumes and assures no single interpretation. ${ }^{12}$ Thus, even when cinema is at its most abstract and materially reflexive, film is not understood ephemerally by the viewer as merely the sum of its physical component parts unless it is constructed by the filmmaker in ordered to be considered as such. ${ }^{13}$

$11_{\text {Judith Butler, "Desire", in Frank Lentricchia and Thomas McLaughlin, eds., Critical }}$ Terms for Literary Study (Chicago, IL: University of Chicago Press, 1995), p. 369. 12 Vivian Sobchack, The Address of the Eve: Phenomenology and the Film Experience (Princeton, NJ: Princeton University Press, 1992), p. 6.

${ }^{13}$ For example, this is how one might describe or experience certain "abstract" films, 
How then might one understand experimental films such as Philip Hoffman's Kitchener-Berlin -- which investigate themes of cultural memory and personal historiography through the self-conscious layering of multiple, seemingly disparate image sources -- as signification? If indeed the cinema makes sensuously and sensibly manifest "the expression of experience by experience," then it would appear that this Canadian experimental film can be seen not simply as a representation of remembering, but more accurately, as signifying the complex perceptual and cognitive processes by which individuals arrive at making memory within culture. This is to say that in this work making sense of the past by bringing together the fragmented bits of archival reference from a "time-not-our-own" in a non-totalising, a-logical way is a complicated process. This is true not only at the level of the subject of conceptual investigation, but also at the surface of the image where meaning is corporeally experienced and constructed through signification. Consequently, the "sense" (of history, of memory, of culture) signalled by the dense layers of images in this film and negotiated by the viewer can be read as an aesthetic allegory for the perceptual processes which enable constructions of meaning. Hoffman's images are allegorical in Butler's sense that they deal with histories and their implications in a manner that is not easily narrativized. Yet this work of allegory is conveyed not in language, but in aesthetics and appearance; the look, the sound, and the arrangement of the film.

\section{Other Histories as Aesthetic Allegory}

Certain compelling visual motifs recur throughout the sonically sparse film Kitchener-Berlin that appear to sensuously signify an "expression of experience by experience", although their meaning is never fully realized. Most noticeable to the eye are Hoffman's slow, sweeping, oft-repeated 360-degree pans of public spaces -- a city

such as David Rimmer's Fracture (1973) or R. Bruce Elder's She is Away (1975). 
parkade, an urban street, an office building -- over which he often lays in footage of expressive faces of people in crowds; images presumably culled from private home movie archives of parades and other civic events. "Juxtaposed with images of the past, the Steadicam is filled with a sense of returning. Because its movement isn't attached to a body or person, and its movement is so uniform, it's as if the ghost of technology had ventured back to visit what it had occasioned, to look over all that's been constructed in its wake." 14

In terms of formal aesthetics, said recurring images can first be read with respect to the structural strategy of the film as a whole, for there are indeed numerous instances in which Hoffman uses optical printing to problematize the singularity of meaning at the surface of the screen. Not only are his images unstable at their "base" in that his pans are disembodied expressions (of the Steadicam) that register in the body and produce disorientation in the viewer, but the address of the images in the foreground proffers merely traces of objects and people that/who are not quite there. ${ }^{15}$ Yet Hoffman's intent is not simply for the viewer to sit in evaluation of the fragile materiality of the film medium itself; he also provides the experiencer with coded images (from both a recognized archival past and that of another time which is [perhaps] rooted in his own autobiography) at which to look. These are loosely organized in terms of a formal structure that is abstract and motivated by a thematic construction. Again, the effect on the viewer initiated by way of the layering of particular image sources is better understood as aesthetic allegory than as narrative, in that the referents of landscape and identity are not entirely connected and never finitely resolved. Hoffman states:

${ }^{14}$ Mike Hoolboom, "Philip Hoffman: Pictures of Home", in Mike Hoolboom, ed., Inside the Pleasure Dome: Fringe Film in Canada (Toronto, ON: Gutter Press, 1997), p. 146. ${ }^{15}$ The same can also be said of certain moments in later meditative Hoffman films like Chimera (1995) and What These Ashes Wanted (2001). 
There's no story, just home movie moments mixed with photographs of Kitchener back when it used to be called Berlin during wartime. Then the film revisits both sites in the present, using a Steadicam camera. It floats over surfaces, looking as if it can move without gravity, gliding in space... It's something we can't do with our bodies, except through technology. So it's a metaphor for the spirit released. ${ }^{16}$

In looking upon the pasts visually represented in Hoffman's film, it is as if notions of history and memory (whether personal or collective) may never be entirely realized. In turn, the very sense we enact so as to discern what memory is, was, or could be (namely, that of the eye and vision) is herein incapable of being focused in any "rational" sense.

In other sections of the film Hoffman explores the arbitrariness of signification at the level of the cinematographic image. Early on in the work he incorporates what appears to be a faded archival photograph of a train station bearing the sign "Kitchener". And yet mere minutes later, following a loosely bound sequence of underexposed home movie images of an iconic 1950s family at play, the same train station image returns to the screen, however this time it bears the sign "Berlin". How then is the experiencer to understand the kind of logic motivating this work of film if, by way of Hoffman's visual metaphor, identifying something in the present-past is always arbitrary and contingent on its signification? Whereas the perceiver of the work is presumably able to access other sites of knowledge existing within the culture (libraries, museums, and the like) in order to sift out the temporal-historical logic behind the shifting "Kitchener-Berlin" sign, ${ }^{17}$ Hoffman's juxtaposed images appear as an implicit challenge to that kind of "rational" history making. His visual allegory is not simply a challenge in terms of questioning the finite results arrived at through linearly motivated historical inquiry, but is also a

16 Hoolboom, ed., p. 145.

17 Thanks to Professors David Douglas and Thomas Waugh of Concordia University for informing me of the fact that this wartime change of the city's name -w which motivates Hoffman's visual reference -- occurred between 1913 and 1914. 
problematization of the way traditional history making is carried out by an uncritical eye focused through the technological apparatus of the cinema. Thus, the artist's revisualisation of past times and places invites the viewer to re-view (the meaning of) historical memory, (in)directly loosening the chains of traditional logic that enable us to make sense.

Wees proposes a line of inquiry into the avant-garde's cinematic equivalents of visual perception that follows two complementary lines of argument. The first of his propositions holds that vision includes or implies many different ways of seeing.

In addition to focused and full-colour foveal vision, there are varying degrees of less focused and colourless peripheral vision, as well as hallucinations, optical illusions, and 'closed-eye vision' (as Brakhage calls it), which includes hypnagogic imagery, phosphenes, and the grainy visual 'noise' perceptible when we are in a dark room or have our eyes tightly closed. ${ }^{18}$

From this emerges Wees' core argument about experimental film aesthetics that he develops throughout his book, as it insists upon what he calls "recognition of a 'visual life"' that includes all possible ways of seeing. With respect to Hoffman's film then, perhaps its layered images are structured both formally and allegorically in order to invite readings of history that are in a sense less focused, such that the film favours the recognition of a "visual life" that is rarely addressed in more conventional media.

Wees' subsequent line of inquiry provides a more interesting avenue for analysis with respect to discerning the kinds of meaning signified in Hoffman's film, as it requires an expanded critical sense of what the cinematic apparatus is capable of producing. His proposal stresses the significance of numerous characteristic, oft-cliched technical conventions of the experimental filmmaker, the most important of them, for the purpose of my analysis, being that of superimposition. Wees notes how this technique has been

\footnotetext{
${ }^{18}$ Wees, p. 3.
} 
historically interpreted by critics and audiences in a variety of ways, although most significantly (and problematically) as merely a subversive gesture against the formally encoded visual language, narrativity, and ideology of the popular cinema. I agree with Wees' acknowledgement that some kind of immediate value is drawn from such cursory explanations. Sharing his search for an unconventional "visual life", I am glad to find another reading of the effect of superimposition, as a means of historiography and epistemology, that has been less readily pursued in criticism.

\section{Seeing the "History" of the Present Through the Limits of Video}

This chapter concludes with a response to recent videos "about" the fringe artist that sees these works as situated alongside the historiographic, epistemological works described in the previous sections. Representations of the marginal Canadian artist as worker, as evidenced in two experimental video productions from the Toronto scene (Steve Reinke's Afternoon: March 22, 1999 [1999] and Work [1999] by Kika Thorne), offer a means of seeing through the contemporary fringe with a sense of socio-political rigour. Both works are theories that invert normal ideas of what is meaningful and productive within culture and society, and in so doing, they demonstrate how artists' lives are full of opportunities for non-sense and encounters with the unthought. Essentially their purpose is to reassess this country's fringe media as "alternative" image-spaces for the theoretical configuration of an imagination outside of the grasp of capitalism.

In the first chapter of his book The Tyranny of Work: Alienation and the Labour Process, historian James W. Rinehart paraphrases Karl Marx to note that, "By changing the world they live in through labour, human beings at the same time alter their own nature, for the lives of people are influenced both by what they produce and how they produce."19 I would like to suggest that scholarly criticism of experimental film and

${ }^{19}$ James W. Rinehart, The Tyranny of Work: Alienation and the Labour Process (Third Edition) (Toronto, ON: Harcourt Brace and Company Ltd, 1996), p. 1. 
video productions in this country might benefit from a more detailed examination of how the contemporary artist produces work (or more broadly, is socially obliged to work), in order to enter into deeper critical negotiations with the socio-cultural "meanings" of what is produced. This is to say that ultimately no production should be seen as homogeneous, as being divided or entirely apart from the complex socio-political situations that brought it into being. Therefore, it is my suggestion that the work of experimental media be considered exactly as such -- as an example of work itself, implicitly critical of the values of the culture on whose margins it is produced. I wish to propose that in looking to/at contemporary marginal arts productions, an audio-visual grammar can be developed so as to recognise how experimental media works inherently "experiment" with larger ideas about labour as projected through the mass culture. Furthermore, these factors should always be brought into consideration when thinking through ideas about experimentalism so as to recognise that the limits by which the "experimental" is defined are always in flux and difficult to define.

For me, no one image speaks to the dilemma of what an experiment is more acutely than the opening of Steve Reinke's 1999 video Afternoon: March 22, 1999, a work which, like most of Reinke's pieces, is deceptively sly and seemingly detached in the way it approaches notions of the personally and socially political. The twenty-two minute piece begins with Reinke surveying the surface of a lens cap held in his hand, such that the contours of his fingers are carefully reproduced by the digital video camera he holds in his other palm. Reinke's camera lingers for what seems a moment unnecessarily long, for as an artist he seems perhaps less fascinated with the crisp, clear image his camera is reproducing (that of skin, with its distinctive wrinkles and contours) than he is with the means of production that brings the corporeal into view. For it should be noted that Reinke's lens cap is (not surprisingly) a branded object/image which bears the ever-recognisable logo of the Sony corporation, which is not entirely divisible, in the metaphor of this instance, from the human being who is holding it up for display. 
This object/image must be read as troublingly significant, for immediately Reinke appears to be situating the viewer within an acute awareness of just how mediated the experientiality of this art piece will be. Reinke's fascination with the brand then can be seen as problematizing notions of what it currently means to be (or at the very least, to work as) a marginal artist. In this regard it is as if the question posed by this object/image is without resolution, or rather (to oversimplify): is this work produced by Reinke or the Sony corporation? Yet more complexly, how exactly does the Sony corporation (or by extrapolation, any media or image-making institution with the design and intent of accruing capital) produce the work of the contemporary artist? Thus, what appears to be most unsettling about this particular object/image is its relation to the themes and ideas Reinke explores throughout the piece which, broadly speaking, explores the surveillance of the domestic and the banal as a means of generating new notions of the creative and the artistic in the face of the (then) imposing millennium. The video, as its title connotes, is literally "about" an afternoon in March spent by way of the camera's lush digital invitation with Reinke in his Toronto apartment as he seemingly "wastes the day away". Yet I would assert that it is his heightened attention to his own seemingly leisurely activity which makes this video so compelling, as the discerning spectator should never lose sight of the fact that here the queer image-maker is at much at leisure playing with his new Sony camera as he is at work, labouring at experimenting with the digital image's limited capacity to record and reconstitute the reality of the everyday. Thus, in light of Rinehart's point that under capitalism "Time without employment is regarded not as leisure but as an unwanted intrusion of idleness, ${ }^{20}$ in this context time is equally subject to the inseparable forces of the social and the economic, as it is reconstituted by Reinke's lackadaisical obsessions with the objects of his and his camera's fascination.

${ }^{20}$ Tbid, p. 6. 
The explicit challenging of the video medium's essence(s) and, interrelatedly, its capacity to represent and reconfigure ideas of the social and political, is not a new phenomenon, whether one looks towards the thirty-year-plus history of work that has been produced or the scholarship and criticism it initiated. Thus, I would like to be clear that I am not claiming that videos such as Reinke's are inherently (or actively, or consciously) subversive in the way their sounds and images challenge notions of the cultural value or "worthiness" of video art. However, what I do wish to assert is that tapes such as these are rather transgressive and (perhaps) progressive with respect to the multiple cultural sites they can be seen as simultaneously occupying. Again, what is intriguing about the "experimental" status of Reinke's tape is that it might be as close to occupying the space of what is deemed a work of art in the age of digital reproduction as it is to being a delicious advertisement for Sony's recent technological innovations, in spite of his camera's fascination with the holes in his sock and dust bunnies, amongst other things. Contemporary fringe works should be seen as situated at multiple sites along a continuum between the potentially revolutionary and the painfully regressive.

Kika Thorne's 1999 video Work echoes this tension, as it was produced for a Toronto festival called "On the Fly" which challenges local video and filmmakers to make a maximum 10-minute long piece in a 24-hour period and then cut it in the same amount of time. And while I hesitate to be too heavy-handed or deterministic in my critique, it should be noted that this particular festival carries with it the overt corporate sponsorship of the Canon corporation, such that each work is shot and edited using the latest in Canon's digital technological developments and is logo-ed as such in the end credits. Thorne is an interesting figure to examine in this context, as while she has a substantial body of work to her credit that is best described as experimental and even activist, here her fringe status is somewhat problematized by the fact that this piece was explicitly produced for a festival which is not only more "mainstream" in terms of the structures of its funding/audience/exhibition etc., but whose mandate is to ensure that all 
"On the Fly" works are narrative by design. ${ }^{21}$ This makes it all the more interesting to consider Work in terms of the various cultural spheres the piece seems to simultaneously occupy, as signified by its loose narrative structure and formal aesthetics.

\section{Video and Dual/Duelling Consciousness}

The subject of Work is a nameless twenty-something woman to whom we are first introduced in split-screen as she sits in an office cubicle, typing earnestly on a computer keyboard and staring at the monitor. The images, while temporally simultaneous, are presented to the viewer from two different points of view with slight degrees of variation. As a result, Thorne's choice of the dual image (which continues formally throughout all of the vignettes in the near ten-minute piece) creates an interesting effect, as if the character were contained from all sides around in spite of the multiple points of view hinted at by the split screen. Even when looked at independently of one another, the sense the shots conveys remains one of isolation, whether through the attention paid to her face in the close-up on the left or that of the frame on the right, which emphasizes the distance between the protagonist and her colleague down the hallway. Furthermore, these shots and their design are also intriguing in the context of the mise-en-scene of the sanitized corporate office and in light of the fact that the doubled image has become a formal convention which appears to signify a "freeing up" of a subject, as if the mere doubling of visual information leads to more knowledge or possibilities. But Thorne's extra image has a compression effect; the more we see the less we know. Here it is intended to signify the character's unwillingness/inability to work (or by proxy, to exist) outside of the confines of the contemporary high-tech/low-opportunity job market. For the viewer learns through her dialogue in the following scene that she is far from pleased

${ }^{21}$ In fact, this is specifically mentioned in their annual call for submission applications, as well as prior to each of the screenings themselves. 
with her situation and is having a difficult time adjusting to her recent move from Halifax to Toronto, a city she finds inclement to socializing and the lives of artists. In fact, she appears to yearn to be elsewhere and to return to where she has been, when she comments to one of her colleagues, "Where there is no work in a place, people have more time to be with each other because they're less busy."

Thorne's protagonist possesses what Rinehart (by way of Marx) would describe as an "alienated consciousness" with respect to her labour. Rinehart's thinking on this issue proves quite useful to this discussion, which is why I will quote him at length.
A complex set of psychological, cultural, and social forces influence the degree to which individuals recognise the sources of alienation, adapt to alienating work, and express -- verbally and behaviourally - their disenchantment with work. Obviously, not all working people are conscious of their alienated position in work organizations in the sense that they are able to locate and articulate the socio-economic factors responsible for it. Just as obviously, many working people regard inequalities of power and wealth as natural and inevitable. But all workers in objectively powerless circumstances do possess an alienated consciousness in that they directly experience and are acutely aware of the effects of structural alienation, such as repetitive and insecure jobs, insufficient wages, and arbitrary work rules. The test of the existence of alienated mental states is to be found not so much in the ability of individuals to articulate the causes of alienation, but primarily in their verbal and behavioural reactions to work. ${ }^{22}$

Interestingly, and in accordance to Rinehart's definition, the figure of Thorne's female artist (as portrayed by Shary Boyle) is signified as embodying an "alienated" position with respect to her labour and, by extension, the classed social space of the electronic workplace she occupies. Again, looking through Rinehart via Marx allows us to assess

${ }^{22}$ Rinehart, p. 14-15. 
how this character, who we learn is also a representation of the contemporary artist, seems (on a cursory level) somewhat able to recognise the sources of alienation and express her disenchantment both in language and (in)action. The question here is, to what extent might this working, classed woman be able to adapt to those conditions? Particularly, the lasting image of her sprawled inert on the couch after having been fired - not for poor job performance, but for her boss' observation that she "look[ed] like [she] didn't want to be here" -- embodies the utter stagnation of resistant thought and action. For here even the formal aesthetics of Thorne's dual/duelling images (which doubles her character's ennui and alienation) are limited in the ways they might indicate how to "free" this coded protagonist from the tytanny of how her work is organised both economically and socially. Indeed, if verbal and behavioural reactions to work speak volumes about alienation, then there is much being "said" in this loosely defined sequence. Thorne uses digital video form so as to express how not even double vision can tell a whole story.

Furthermore, the video works as a theory of how there is more fulfilling "work" to be done within culture than in the office, though these activities rarely come with any kind of monetary remuneration. I am referring to the non-sequential series of vignettes later in the tape following her firing, in which she engages in various pleasurable activities like a frenzied makeout session and riding a bike with a friend while singing. Strangely, there does appear to be a (loose) measure of narrative closure to Work, as Thorne's final image is of her character smiling while concentrating on painting. This implies that she has finally chosen/accepted a kind of happiness outside of (or on the fringes of) a culture which only values her labour and experience inasmuch as it is commodifiable. Thus, the video is "about" what kind of work, and play, are meaningful in anti-capitalist terms. 


\section{The Problem of Politicization}

I will conclude with the observation that recent film and video works such as these can be read as manifestations of an "alienated consciousness" with respect to the socio-political significance of contemporary experimental production. Contemporary artists, to varying degrees, are themselves alienated, though they also knowledgeably express their alienation through their work. Videos such as Reinke's Afternoon, and to a lesser extent Thorne's Work, point to how discourses of (and surrounding) the fringe are having a difficult time of late in determining where they are and where to go next.

However, these artists are contributing to the vibrancy of this debate by making intellectual works that worry the question of corporate dependency and its effects on (artistic) culture. Gary Kibbins notes in an essay that accompanied the 1997 "Flaming Creatures" video exhibit at the Agnes Etherington gallery in Kingston, Ontario:

What makes the assessment of contemporary work difficult at this stage is that both the character and significance of what is 'experimental' is itself changing. Gone is the relative stability of the more programmatic forms of modernist experimentation; our experiments are at once pluralistic (we allow a proliferation of discrete forms) and heterogeneous (these forms ceaselessly impenetrate and transform each other). It's just our appraisal of the results are different. ${ }^{23}$

Kibbins also notes two other trends that should be tied in here, which $\mathrm{I}$ believe must be explored elsewhere in greater detail. First, Kibbins points out how in spite of sharing a technology with commercial interests, early video artists somehow saw themselves as free to demonstrate a level of aesthetic and intellectual independence where the demands of the marketplace (be it art or commercial) were remote and where one could exercise an anti-capitalist imagination. Not surprisingly this argument has lost much of its allure,

${ }^{23}$ Gary Kibbins, "Flaming Creatures: New Tendencies in Canadian Video", in Steve Reinke and Tom Taylor, eds., Lux: A Decade of Artists' Film and Video (Toronto, ON: Pleasure Dome and YYZ Books, 2000), p. 48. 
arguably as a consequence of the suffocating emergence of global transnational economic interests and the subsequent effect that little that is "marginal" appears to be safe from corporate assimilation and appropriation. Video art incessantly continues to contribute -- via its makers and critics -- to discourses concerned with identity and multiplicity, be it gay/lesbian/queer/transgendered or postcolonial concerns, to note but a few marginal socio-cultural positions which continue to be surveyed so as to investigate larger cultural meanings within. This raises the question: are identity politics a decoy from the vast problem of globalization? ${ }^{24}$

However, in the same essay Kibbins notes that experimental video practice and its discourses have rarely concerned themselves with other (allegedly) more universal, oppositional interests such as that of labour. Which leads to the question: why are issues of work and class (or by extension, cultural history) so difficult to represent, even in the supposedly "progressive" institution of fringe image-making? And furthermore, what images or ideas might a critical experimental practice contribute if its makers and thinkers were to rigorously approach the complex, often troubling issue of the interrelatedness of labour and class as it is defined under capitalism in countries such as Canada? It is time to enact a more historically oriented understanding of video as a complex cultural site, whereby issues of labour and class are worked through as works of art. Perhaps Kibbins' acknowledgement that "the potential to use video to develop a noncommercial culture still remains at the heart of what a critical video practice is" 25 could now be complexly enacted in a laboratory for progressive visual and audio experiments

\footnotetext{
${ }^{24}$ I am by no means the first person to raise this question, as this has been suggested by writers ranging from academics like Cubitt and Donna Haraway to journalists like Naomi Klein. Also, artists John Greyson and Richard Fung both touched on how the politics of difference get consumed by global capitalism during their respective talks at the October, 2001 conference "Blowing the Trumpet to the Tulips: an exchange of experimental media" at Queen's University.

${ }^{25}$ Kibbins, p. 47.
} 
which go beyond reacting to and criticisizing the ill-effects of capitalism and that might, in turn, produce theoretical tools for the labour of social resistance.

In this regard, recent Canadian works such as Kika Thorne's Work and Steve Reinke's Afternoon: March 22, 1999 proffer meaningful (albeit conflicted) perspectives from which to assess the lived role of the artist in contemporary culture. While Reinke's piece is structured more as a diary-like documentary and Thorne's work initiates a temporally loose day-in-the-life fiction, both videos problematize notions of what it means for the marginal artist to work in the context of the (supposedly classless) "new knowledge economy". Essentially, these videos raise questions as to the "use value(s)" of contemporary art as cultural capital and speculate that emotional labour might be better spent in our intimate relationships with the world around us than in the confines of a corporate cubicle. It is commodity culture, which produces artists' and other peoples' economic needs, that is dictating that product is more important than process. Hence, any definition of "experimentalism" which does not respond by valuing process over product, or uselessness over usefulness, or, in Deleuzean terms, non-sense over sense, is ultimately misguided. ${ }^{26}$ While these works do address their own complicity within the market economy, as indicated by Reinke's Sony logo or Thorne's Canon sponsorship, they operate theoretically so as to initiate an audio-visual space for imagining social change, inasmuch as even the smallest battles against capitalism are worth fighting.

\footnotetext{
${ }^{26}$ Concepts such as "uselessness" and "process" are of course, inherited from historical avant-garde theory and practice, though I would argue that this legacy needs to be reinvigorated in a contemporary context so as to investigate the possibility of further change and growth.
} 


\section{Chapter 4: Conclusion}

Being contemporary means to be with "the times" or rather, in the "now". However, as I recently sat down to write a conference paper for a panel aimed at discussing generational shifts in the production of fringe media works and the social and critical discourses which surround(ed) these changes, ${ }^{1}$ I struggled to grasp the notion of "the times". What are they exactly and more specifically, what are the principles and practices which influence and mediate the experience of their passage? It is my intention here to argue in favour of sense, or specificity, in understanding my particular experiences of recent events rather than resorting to abstractions. I hope that my thoughts can be situated within the broader context of these debates. I wish then to begin my conclusion with a brief examination of the politics of "the times", specifically with respect to what the contemporary media artist is and should be attuned to both in practice and in theory. Conversely, I am also heighteningly aware of what divergent times "the times" comprise, which leaves me to simultaneously consider whether there are indeed materials, ideas, events which are left out of the conventional discourse of "the times" -lingering as possibilities, lying just beneath their constructed surface. How then might the fringe address and inform these alternate conceptions of "the times"?

On July 7, 2001, at an Ottawa Art Gallery symposium entitled Re(p)lay and Retroaction: The 1960s, Revolution, and/in Contemporary Culture, filmmaker and scholar Gary Kibbins commented, "We need to extend the period of experimentalism to see where it goes." This declaration implicitly calls for an expansion of the tensions that exist between art, politics, and the realm of the social in favour of an experimental practice which is process-oriented and "useless" by design. His statement emerged from a debate following his talk entitled "Work \& Anarchy" that detailed how the historical

\footnotetext{
${ }^{1}$ This inter-generational conference panel kicked off "Blowing the Trumpets to the Tulips: an exchange on experimental media", in October, 2001 at Queen's University in Kingston, $\mathrm{ON}$.
} 
avant-garde (the Dadaists, the Situationists) made art so as to vigourously respond to the cultural ambivalence towards work, particularly physical labour associated with the necessities of life. His statement is well-taken, in that our current times appear to be such that we are in need of an avant-garde (or what I have chosen to call a "fringe") of renewed cultural significance, which produces aesthetic works which somehow avoid overt commodification, as I argued in the previous chapter. The very fact there is such a need implies whatever period of artistic experimentalism we are currently in is predisposed to playing through the current cultural situation to get through to... well, whatever is next. Therefore, let me pause to scrutinize the discursive and practical terms by which we continue to define "experimentalism" and the limits at work therein.

One must acknowledge that a significant portion of fringe media (more so within video than film) made in the previous "generations of the (to borrow Mike Hoolboom's term again) was formally and aesthetically dependent on the centre, or was being produced with the implicit/explicit agenda of problematizing the codes of mainstream ideological mastery. Thus you can pick and choose amongst examples from whatever era (the tapes of Vera Frenkel and Lisa Steele from the late 70s and early $80 \mathrm{~s}$ that I discussed in my first chapter immediately come to mind) but one theme remains -that the makers of these works often enacted irony so as to borrow from or hijack the codes, conventions, politics, aesthetics of more dominant sites of address and ways of seeing (read, the mainstream) in order to make their artistic work. As I wish to point out, this just is not enough anymore. John Champagne's description of marginality helps us to understand that fringe work has always been made simultaneously alongside/against its conventional counterparts in the mainstream. However, the shifting socio-economic realities of "the times" necessitate that experimental media artists respond accordingly, and they do so currently by contributing to the crafting of "useless", affective space(s) within the broader cultural sphere. 
Recall my criticisms of Jenny Lion's description of "Canadian" experimentalism as "always taking risks" from my introductory chapter. Her program notes imply that all experimental works at all times are always in the process of taking risks, which is problematic given that the fringe's themes and strategies are indeed transformed by the differing needs of a historical era. Furthermore, to say so limits the terms by which we try to define experimentalism as something other than a genre or a collection of effects. Lion's contextualization of experimentalism does not allow these works to not "succeed", to be other than "risky", or to breathe if you will. Rather, experimental works are always seen as "meaningful" when looked at phenomenologically, even though the meaning(s) of these works and responses to them shift in accordance with the politics of "the times". Thus, experiencing earlier tapes such as Frenkel's demonstrate that her art's relationship to the unthought or the non-sense was different then than now. In looking at her videos phenomenologically, through a subjective analysis of their affective qualities, we can see the ways in which works from previous eras related to the unthought and can help us do the same in a contemporary context. I generally find Lion's description of experimental works discursively limiting and enframing, which is definitely not her intention as a curator of a retrospective of Canadian video art.

That being said one idea does stand out from Lion's comments in terms of loosely defining experimentalism, and that is her notion that something is "at stake [in] the act of invention". Implicitly, the act of trying something carries with it an inherent cultural value regardless of how it turns out. This reduces the complexities of my earlier point about Razutis and Falardeau to a critical position whereby one can simultaneously acknowledge that these artists experimented with the medium of video, yet whether or not that past experiment is still of cultural value or importance is moot, as it is the act of experimentation which mattered and continues to matter, and not the end result. This description of experimentalism allows us to move towards considering the making of contemporary time-based art as "laboratory work". Another way to state this could be, 
"The aesthetic of 'making do' with a time and a space that are no longer considered abstract, utopian, or alternative will allow us once again to create, represent, and project ourselves as subjects into a History that seems to do very well without us." 2 Thus, defining the practice of experimentation as "making do" embraces Gilles Deleuze's logic of sense inasmuch as it emphasizes the value of "uselessness" inherent in the present tense. Similarly, fringe works do not (and should not) necessarily have to lead somewhere or be quantifiable in their end result, as it may not even be possible to assess this. For example, there is a video from 1996 by Susan C. Rynard entitled Eight Men Called Eugene that I would argue functions as an allegory for how (as a culture) we need to experience, participate with, and produce the fringe in a non-sensical and loose manner. The tape is stylistically structured in the form of a faux documentary in which a female genetics scientist walks us through a high-tech laboratory so as to explain how the evolution of the human genome project is equal parts progressive technological development and a not-so-humorous teleological coincidence. For you see, Rynard's Eight Men attempts to adapt the slick production look and generic conventions of the corporate infomercial so as to interrogate the limits of how we subordinate audio-visual experience to instrumental ends. In responding to the tape's expressions affectively, which is a relationship mediated in part by how we subjectively view the shortcomings of the work's "professional-looking" aesthetics, we open up a way of seeing how Rynard's experiment relates to the unthought. Her replication/co-option of mainstream conventions in order to invert their ideological implications is an example of "making do", in that the work opens up the space of how our knowledges are fallibly constructed, which in this instance relates to the notion that the social and political construction of

\footnotetext{
${ }^{2}$ Jean-Charles Massera, abstract, "Towards and Aesthetic of 'Making Do"', $\operatorname{Re}(p)$ lay and Retroaction: The 1960s, Revolution, and/in Contemporary Culture (Ottawa Art Gallery, July 7th, 2001).
} 
"knowledges" sometimes manifest results of grave significance; read: contemporary genetic engineering as an extension of Eugenics.

\section{Too Much Art/Not Enough Utopia?}

Unlike the historical avant-garde that Kibbins described in his talk "Work and Anarchy", the contemporary fringe artist does not appear to be (falsely) captivated by the possibility of realizing utopia. This stance is made quite literal within the discursive strategies of productions such as Work (1999) and Afternoon (March 22, 1999) (1999), which I discussed in the previous chapter. In the latter work, the artist/narrator Steve Reinke invites an affective response to the tape by asking his audience to think of its ephemera as "a jazz improvisation after years of experience making other compositions". Included in the work's loose structure, which is mediated by Reinke's exploration of incamera editing and the technological limitations of his recently purchased digital video camera, is a section in which he wonders whether there is just too much art currently being made. The viewer affectively experiences Reinke's struggle to get the camera to focus on a colour slide that he juxtaposes with his apartment window, because a test of good art is "If looking at a work is more interesting than looking outside." Once he achieves focus, he comments, "I want to make good work but I don't think it is possible at this time... All we can do is wait, cower and wait." He goes on to note that "This century has played itself out", which is a coy spatially-and temporally-specific reference to the mass media driven anxiety surrounding the new millennium that was, at the time he made Afternoon, more than nine months away. However, it is also a playful/sombre speculation on what the future (of art) might possibly bring that implicitly asks: what kind of art is currently being produced out on the fringe(s)?

One could make the "too much art" argument about how the contemporary fringe merely produces a parade of references to its own disjointed and marginal history, and in 
doing so, becomes increasingly disconnected from the social. ${ }^{3}$ In this regard, perhaps the "art school problem" of how critical and institutional strategies lead to the problematic canonization and museumization of certain works has reached its unflinching end? However, Reinke's tape and his comments therein allude not only to how there is much left to be done with respect to the fringe production of (cultural) theory, but that contemporary art should be (and is) up to the task. ${ }^{4}$ The work is experienced not as a eulogy for the impossibility of (art) realizing utopia, inasmuch as it reinvigorates the need for fringe alternatives to the mainstream and its politics of representation (in terms of progressive viewership positions or "visual grammars", if you will) that do not problematically determine the Other. In their own ways videos such as Afternoon, John Greyson's Pack'n (2001) and Gary Kibbins' Carl Andre's Overalls (2000) demonstrate that artists' alternatives need to be produced and are continuing to be brought forth. Thus, to play out the scenario that ours is an era in which "everything is derivative" or "been done before" could be a fair, cursory assessment of fringe media, though this argument can be dismissed if it is consistently followed through. As I have shown here, in conjunction with my earlier re-configuration of Lion's definition of experimentalism, all fringe experiments (from whatever era) are valuable and can be experienced anew. An affective response is progressive in that it both respects the original values of the work and allows the viewer to change its meanings and be changed by them.

\footnotetext{
${ }^{3}$ I am interested, in this context, to see the criticism that emerges following the October, 2001 debut of Charles St. Video's blahblahblah program, which comprises nearly a dozen artists' videos shot during the FTAA protests last April in Quebec City. ${ }^{4}$ This is particulary apparent and pertinent when one looks at the emerging scholarship around low-tech, "under-the-radar" works. My supervisor Laura U. Marks' paper "Invisible Media", which she presented at "Blowing the Trumpet to the Tulips", addresses these issues and will soon be published in a forthcoming Routledge anthology entitled Digitextuality: Theses on Convergence Media and Digital Reproduction, Anna Everett and John T. Caldwell, eds.
} 
In this context, even contemporary works which are reactive in their polemical structure have some "value" to them, particularly in how they expose the limits of irony, which has long-dominated Canadian cultural production. In Jubal Brown's The Blob (1999), the tone of the narrator's sinister, nasal voice in conjunction with his choice of language, which equates participating in mainstream culture with being "slaves" or "zombies", together create a confusing barrier to making sense of the work's jarring aural and visual montage. The images, plundered from broadcast television and edited in the jagged, cyclical style of Istvan Kantor's Jericho (1991) or Accumulations (1999) -- think of the image equivalent of a DJ scratching a record - intend to generate a sense of the (post?) apocalyptic panic that radiated throughout culture at the time of its production, though with a more explicit political intent than in Afternoon. Brown's random loops and blips do sever the logic of suturing ideology to image that permeates the TV screens kept in suburban basements across North America. And yet, the narrator's words are (intentionally?) over-performed to the extent that they neither serve to rally the audience to attack the tyrannical hegemony of the mass media, nor do they provide the viewer with the "out" of ironic dark comedy. Our reception of its aggressive affect is unsettling inasmuch as the video, while demonstrating that tweaking the representational codes and conventions of mastery inherent in mass culture is formally and aesthetically possible, collapses the possibility for social and political subversion. The work's expressions insist that criticism of the centre also implies compliance. The potential problem, then, seems to be that ironic contemporary fringe works like The Blob (or, to a lesser extent, Eight Men Called Eugene) become black holes that spiral into negativity, whereas what the fringe needs is enough energy to spiral out into the new, the unknown. This seems to be the issue with some current fringe artists as negativity, or critique, is necessary but not sufficient for the "new" to come into being. Plus, we also know that irony is instantly incorporated by capitalism. Which raises the question: where can that energy, to spiral out, come from (now)? 


\section{Fringe Art-Making, Digitalism, and the Problem of Capitalism}

Contemporary works demonstrate that while art might not be able to "defeat" capitalism, artists do need to be "smarter" than capitalism, which engulfs and incorporates everything to its purposes. As I have argued earlier, subversion and critique are inside-concepts, problematically lodged against the outside that is the mainstream. Similarly, I have noted how current fringe works are experienced as theoretical models for a kind of experimentalism that is more "autonomous" in its representational strategies and not so reliant on the mainstream as its mirror, its foil. This is precisely what scholars like Kibbins and Cubitt argue that contemporary media artists need to further develop. The latter even offers his own Deleuzean model of a new "digital aesthetics" that evaluates work not in terms of internal consistency, of wholeness (for wholes get eaten), but in terms of its openness, for the open is not easily incorporated. ${ }^{5}$ Cubitt demonstrates how in the digital age it is less effective than ever to merely subvert or critique the codes of the mainstream, as what is beneficial is the crafting of "useless" media which is more autonomous and less intent to crack the mirror that is the centre.

A related problem of the age of digitalism is that contemporary media artists, unlike the fringe video and filmmakers of previous generations, have not only had to contend with a loss of indexicality (which is to say the difficulty or veritable impossibility for the film/video image to connect with, point to, and/or represent a reality which exists in extraction and proximity) but, more pertinently, the fact that capitalism has produced a world that is already saturated with "too many" images. There are numerous elements which are significant about this shift, though in experimenting with the conditions produced by these changes, the fringe artist develops affective paths to the "new". In this light, a world which is clogged with commodified media (both sound and image-based) can be seen, optimistically, as a database for artists. If it is true, as some

\footnotetext{
${ }^{5}$ See Sean Cubitt's Digital Aesthetics (London, UK: Sage Publications, 1998). p. xi.
} 
assume, that all images have already been made then, as Lev Manovich would say, ${ }^{6}$ the task of the artist now is to create, not just react. One way of creating involves developing new affective "interfaces" to the database of already-available commodity-images in order to develop meaningful "sorting mechanisms".

Indeed, if after the death of God [Nietzsche], the End of grand Narratives of Enlightenment [Lyotard] and the arrival of the web [Tim Berners-Lee] the world appears to us an endless and unstructured collection of images, texts, and other data records, it is only appropriate that we will be moved to model it as a database. But it is also appropriate that we would want to develop poetics, aesthetics, and ethics of this database. ${ }^{7}$

Manovich's idea applies in particular to many recent fringe works, though Ho Tam's 99 Men (1998) is a good example in how the video presents the viewer with a series of 99 portraits of Asian men organized so that each photograph appears slightly out of focus. The 3-minute piece is sutured together with light string music that seems to have been hijacked from an Asian melodrama, giving a simultaneously whimsical and menacing tone to Tam's work, as the experiencer is gradually obliged to make meaning of this expressive interrelationship. As a result, $99 \mathrm{Men}$ can be seen on one level as an interface which alludes to the politics of racial profiling, in that the artist is asking the viewer to examine the stereotype of how all Asian men presumably look alike. The images of these men have indeed already been made (and likely reproduced countless times in yearbooks, magazines, or perhaps mugshot albums), though Ho Tam's intent is neither to make new images, nor to identify an indexical relationship between the photos and a specific historical past. Rather, he is using the medium of video as a theoretical "sorting mechanism", a homoerotic interface to a racist database that gives us meaningful

6I am thinking of two essays by Manovich. Both "Avant-Garde as Software" (1999) and "Database as a Symbolic Form" (1998) can be found online at www.manovich.net. ${ }^{7}$ Manovich, "Database as a Symbolic Form" (1998), p. 1. 
insight into how all databases are organized and carry messages as to how they are to be used, by whom, and to what end.

Perhaps the fringe, the underground, needs to be reinvigorated as an explicitly anti-capitalist space, insofar as capitalism instrumentalizes meaning and requires images to be ideologically "useful". Purportedly, one of the supposed "defining" conditions of the medium still being taught (definitely in academia's historicizing terms, and when you look specifically to the beginning of video and the aspirations of artists ranging from Nam June Paik to Vito Acconci to Joan Jonas) is that fringe works were/are not made for profit. $^{8}$ Even more overt anti-capitalist discursive strategies within fringe production communities do seem possible and might prove quite fruitful, especially in the way this practice could tie in with broader contemporary social movements such as that of labour, students, the working class, anti-poverty, and anti-globalization activists. However, anticapitalist space is not the same thing as non-commercial space. Ultimately, capitalism is about encoding, framing meaning, and making meaning "useful" - often in terms of exchange-value, which is highly problematic. While non-profits often engage in this as well in their own small (different) ways, what the fringe does best is to uncode, to make useless work in the construction of a cinema of playful misunderstanding, of feeling, non-sensicality, and inconcise experience.

\section{The Cultural Value of (Canadian) Fringe Experientiality}

In her essay entitled "Melodrama Revisted" (1998), Linda Williams theorizes that the history of mainstream Hollywood cinema is founded on a melodramatic narratology that effaces "real" tragedy so as to be accessible and discernible to a mass audience.

\footnotetext{
${ }^{8}$ See Martha Rosler's 1990 essay "Video: Shedding the Utopian Moment" for a nuanced re-thinking of video art history's earliest defining moments. It can be found in the Doug Hall and Sally Jo Fifer collection Illuminating Video: An Essential Guide to Video Art (New York, NY: Aperture/Bay Area Video Coalition), pp. 31-50.
} 
Williams is but one of many critics who argue that we need to determine what use audiences make of a cinematic work. Subsequently, she argues for the purposeful use of an embodied response: that the audience's investment is not one of rational interest in a "story" but an embodied response to affect which, in the context of the Hollywood cinema, has the use-value of binding viewers to the American ideology that the individual can triumph over social injustice. To re-work this argument for my discussion, what is the purposeful use of embodied responses to the fringe? What is its socio-cultural "use value", if you will, in terms of what those who experience it "get out of it"? Williams speaks about pathos as a reason for why the Hollywood audience is there and experiences those kinds of films, what they get from their spectatorship. While it is clear that the fringe does not have the same purposiveness, her essay causes me to wonder: why is the fringe audience there?

I wish to assert that an affective response to experimental media need not be instrumental, as it is in Williams' description of melodrama, but can exist for its own sake, in the form of unbounded emotion and embodied feeling, or energy. In Chapter 2 I described seven affective categories that demonstrate how the particularities of a fringe work's form and content (the thingness of the light and image on screen in tandem with the sound bouncing about the no doubt, poorly renovated auditorium) inform the particularities of what the viewer experiences phenomenologically. My answer, then, is that the fringe audience is there to translate, to make "sense" of experimental works in order to elicit questioning, or just freedom. These are phenomena which are only traceable or readable through bodily experience, thus the affective analysis of fringe works offers up a way to get beyond ideology critique, which, as I have argued, mainstream media now incorporates because there is no "outside" anymore (if there ever was). Bodies are particular (subjectively constructed, located, and lived) and can respond in particular ways. Again, it seems the particularities of sensory experience while "taking in" fringe works is what must be stressed, as it allows one to look for what 
Deleuze calls the sensible, the resolutely particular. In doing so one must look to and produce fringe works that signal a shift towards a distinctive cinematic experientiality. There must be a balance between the need for malleable utility and practicality -- of having an other-than-capitalist cinematic space that engenders thought, emotion, action, solidarity -- with the awareness that to make fringe works too useful is beside the point.

Nevertheless, the "mainstream" (which is not as homogenous as one might think) is clearly purposive -- it is for something, whether to sell things, to sway, to manipulate, to impart ideology, or to "move us" (as in Williams' understanding). So again, what is the fringe for/should it be for? My response is that the cultural value of fringe work is that it should never be finitely pinned down in terms of the particularities of what it is about or wants to be about for the spectator who perceives it. Again, in Chapter 2 I noted my alignment with cognitivism to the extent that I believe fringe works are constructed so as to be made sense of, though more significantly, I also emphasized that the experience itself in its "uselessness" is more important than generating useful knowledge(s) sutured to ideology, which is the goal of most cognitive approaches. For example, in this context, my earlier affective analysis of Susan C. Rynard's 1999 video The Day Jesus Melted emphasizes how it is fun, playful, sinful, serious - it is all of these things and none -- it is many things. The video, in Deleuzean terms, makes a sensible rather than an abstract connection. The work must be felt, in its particularity. Thus, rather than making sense of a work in terms of "decoding" it, fringe audiences make it sensible in their bodies.

Even still, the mainstream has changed! Formally and aesthetically it has long since incorporated the codes and conventions of the avant-garde, though of course it remains ideologically inflected. Arguably, the stark social and political consequences of linking capitalism to systems of communication, expressivity, and visuality are more pronounced now than ever before. The same digital cable revolution which appears to offer choice offers very little but the truth that choice is not (currently) ours to have - it 
is concentrated and elsewhere. In the context of the histories that Kibbins' talk described, which encompass anarchism and the Situationists' idea of art-making as a defiant "non-labour", one assumes that the fringe and its artists should/could be leading a resistant, productive response to the phenomena of transnational global capitalism. Works such as 99 Men, Afternoon, and Pack'n demonstrate that the fringe is currently responding, minus the end goal of utopianism that dogged earlier generations, but can experimentalists do more?

The question about generational differences I was provided as a means to focus my discussion for the "Tulips" conference panel caused me to wonder if "younger artists should (in fact) learn their history". Well, in terms of the fringe, the history that is being taught has (to this point) lacked a sufficient affective methodology to help make sense of experimental works as vibrant expressions of (cultural) theory. This absence of a doubly articulated model for experiencing fringe media has produced a critical viewership whereby the avant-garde can only be historicized on a scale that slides between how previous productions and the movements they were produced within were both a "success and failure". Success in the sense that -- "once upon a time not your own" -artists used to think that making film in a certain manner would change the way people thought about and behaved within the world; and failure in the sense that, once those films were made, ultimately the art-for-social-change experiment failed and the world stayed the same regardless. While there are critics and theorists (like William C. Wees in particular $\left.{ }^{9}\right)$ who, in a different way, have proposed alternate or shifting views of a history of the fringe, I would argue that we need to further an understanding of ways of experiencing how the fringe's supposed "failure", in terms of being co-opted into

\footnotetext{
9I am thinking of the talk Wees gave at the 'Tulips' conference, which was an extrapolation of a paper he published previously, entitled "Carrying On: Leslie Thornton, Su Friedrich, Abigail Child and American Avant-Garde Film of the Eighties," in Canadian Joumal of Film Studies vol. 10.1 (2001), pp. 70-95.
} 
mainstream aesthetic hegemony, can be seen as a worthwhile "success", due to the notion that there can now be a clean slate for artists to work with in the present.

The need for a shift in how we not only experience, but theorize and historicize the fringe, becomes all the more significant within the broader context of the ongoing debates about the relationship between Canadian identity and audio-visual expression(s), which I addressed in my introductory chapter. Historically, the works of our nation's filmmakers have predominantly been criticized so as to determine how they evoke "Canadianness", though paradoxically I would argue that the abundance of these approaches to doing so have merely limited the terms by which we can even trace meaning(s) inherent in the affective essences of Canada's cinema(s). Most critical responses to Canadian film and video suture "understanding" this kind of cultural expression to a cinematic wholeness, to support the idea that, our nation -- though particular in the specificities of its regions, classes, ethnicities, etc. -- is realizable as a whole. In contrast, I have argued for an affective model of Canadian experimental media that does not reduce the particularities of a film or video's form, aesthetics, or content to any kind of instrumentalism. Furthermore, as I argued in Chapter 3, this phenomenological approach respects fringe films and videos as theoretical works. In doing so, it is my belief that the "Canadianness" of this approach (which is selfconsciously subjective, shifting, and situational) is useful and purposive in how it opens up the ways in which we experience and discursively describe audio-visual phenomena, from both the fringe and beyond. 


\section{Works Cited and Consulted}

1996 Video Reference Guide Catalogued by Vtape. Toronto, ON: Vtape, 1996.

Adams-Schimpl, Catherine. Economy of Vision: Adjusting Identity in Canadian Cinema. Toronto, ON: York University/School of Social and Political Thought. (Unpublished $\mathrm{PhD}$ candidate's paper).

Antin, David. "Video: The Distinctive Features of the Medium." In John Hanhardt (ed). Video Culture: A Critical Investigation. Rochester, NY: Video Studies Workshop Press, 1986 [1975]. pp. 147-166.

Ballard, J.G. "Introduction to Crash." Re/Search. Nos. 8/9, 1984 [1974]. pp. 96-98.

Belton, John. "Looking Through Video." In Michael Renov and Erika Suderberg (eds). Resolutions: Contemporary Video Practices. Minneapolis, MN: University of Minnesota Press, 1996. pp. 61-72.

Bergson, Henri. Matter and Memory. Margaret Paul and W. Scott Palmer (trans). New York, NY: Zone Books, 1988 [1896].

Berland, Jody. "Video - Language - The Common/Place." In Peggy Gale and Lisa Steele (eds). Videe reView: The (best) Source For Critical Writings on Canadian Artists' Video. Toronto, ON: Art Metropole and Vtape, 1996 [1986]. pp. 126130 .

Butler, Judith. "Desire." In Frank Lentricchia and Thomas McLaughlin (eds). Critical Terms for Literary Study. Chicago, IL: University of Chicago Press, 1995. pp. 369-386.

Champagne, John. The Ethics of Marginality: A New Approach to Gay Studies.

Minneapolis, MN: University of Minnesota Press, 1995.

Cubitt, Sean. Digital Aesthetics. London, UK: Sage Publications, 1998.

Timeshift: On Video Culture. New York, NY: Routledge, 1991.

Videography: Video Media as Art and Culture. London, UK: Macmillan Education Ltd, 1993.

Davis, Douglas. "Filmgoing/Videogoing: Making Distinctions." In John Hanhardt (ed). Video Culture: A Critical Investigation. Rochester, NY: Video Studies Workshop Press, 1986 [1977]. pp. 270-273. 
Deleuze, Gilles. Cinema 1: The Movement-Image. Hugh Tomlinson and Barbara Habberjam (trans). Minneapolis, MN: University of Minnesota Press, 1986.

Cinema 2: The Time-Image. Hugh Tomlinson and Robert Galeta (trans). Minneapolis, MN: University of Minnesota Press, 1989.

Eoucault. Sean Hand (trans). Minneapolis, MN: University of Minnesota Press, 1988 [1986].

The Logic of Sense. Mark Lester (trans) and Constantin V. Boundas (ed). New York, NY: Columbia University Press, 1990 [1969].

Douglas, David Andrew. The Toronto Avant-Garde at Twilight:Avant-Garde

Cinema in Toronto, 1975-1985. Chicago, IL: Northwestern University, 2000. ( $\mathrm{PhD}$ dissertation).

Elder, R. Bruce. The Body in Film. Toronto, ON: Art Gallery of Ontario, 1989.

"The Cinema We Need." The Canadian Forum. Vol. 64:746, February 1985. pp. 32-35.

Image and Identity: Reflections on Canadian Film and Culture. Waterloo, ON: Wilfrid Laurier University Press, 1989.

Ferguson, Bruce. "Preface." In Canada Video - Colin Campbell, Pierre Falardeau/ Julien Poulin, General Idea. Tom Sherman, Lisa Steele. Ottawa, ON: National Art Gallery of Canada, 1980. pp. 9-11.

Foucault, Michel. The Order of Things: An Archaeology of the Human Sciences. New York, NY: Vintage Books, 1970.

Gale, Peggy. "A History in Four Moments." In Janine Marchessault (ed). Mirror Machine: Video and Identity. Toronto, ON: YYZ Books \& CRCCII, 1995. pp. 55-66.

Videotexts. Toronto, ON: The Power Plant Contemporary Art Gallery at Harbourfront Centre/Wilfrid Laurier University Press, 1995.

Gale, Peggy and Lisa Steele (eds). Video reView: The (best) Source For Critical Writings on Canadian Artists' Video Toronto, ON: Art Metropole and Vtape. 1996.

Gidal, Peter. Materialist Film. New York, NY: Routledge, 1989. 
Hanhardt, John (ed). Video Culture: A Critical Investigation. Rochester, NY: Video Studies Workshop Press, 1986.

Harcourt, Peter. "The Canadian Nation - An Unfinished Text." Canadian Journal of Film Studies. Vol. 2:2/3, 1993. pp. 5-26.

Henighan, Tom. Ideas of North: A Guide To Canadian Arts and Culture. Vancouver, BC: Raincoast Books, 1997.

Hoolboom, Mike. "A History of the Canadian Avant-Garde in Film." In Rose Lowder (ed). The Visual Aspect: Recent Canadian Experimental Films. Editions Des Archives du Film Experimental d'Avignon, 1991. pp. 29-45.

Inside the Pleasure Dome: Fringe Film in Canada. Toronto, ON: Gutter Press, 1997.

Plague Years: A Life in Underground Movies. Steve Reinke (ed). Toronto, ON: YYZ Books.

Hutcheon, Linda. Splitting Images. Toronto, ON: Oxford University Press, 1991.

Jonasson, Catherine and Jim Shedden (eds). Recent Work From The Canadian AvantGarde. Toronto, ON: The Art Gallery of Ontario, 1988.

Keohone, Kieran. "Symptoms of Canada: National Identity and the Theft of National Enjoyment." Cineaction. No. 28, 1992. pp. 20-33.

Kibbins, Gary. "Bored Bedmates: Art \& Criticism at the Decade's End." Fuse Magazine. Vol. 22:2, Spring 1999. pp. 35-42.

"Flaming Creatures: New Tendencies in Canadian Video." In Steve Reinke and Tom Taylor (eds). Lux: A Decade of Artists' Film and Video. Toronto, ON: Pleasure Dome and YYZ Books, 2000. pp. 45-54.

Kroker, Arthur. "The Moose Jaw Postmodern." In Catherine Jonasson (ed). Richard Hancox: Exhibition Catalogue. Toronto, ON: The Art Gallery of Ontario, 1990. pp. 41-47.

Technology and the Canadian Mind: Innis/McLuhan/Grant. Montreal, PQ: New World Perspectives, 1989.

Lipset, Seymour Martin. Continental Divide. New York, NY: Routledge, 1990. 
Lowder, Rose. "Another Level of Perception." In Rose Lowder (ed). The Visual Aspect: Recent Canadian Experimental Films. Editions Des Archives du Film Experimental d'Avignon, 1991. pp. 67-79.

Manovich, Lev. "Avant-Garde as Software." www.manovich,net. 1999.

"Database as a Symbolic Form." www.manovich.net. 1998.

Marchessault, Janine (ed). Mirror Machine: Videe and Identity. Toronto, ON: YYZ Books \& CRCCII, 1995.

Marks, Laura U. The Skin of the Film: Intercultural Cinema, Embodiment, and the Senses. Durham, NC: Duke University Press, 1999.

Matthews, Robin. Canadian Identity: Major Forces Shaping The Life of a People. Ottawa, ON: Love Printing Service, 1988.

McLuhan, Marshall and Bruce Powers. "Epilogue: Canada as Counter-Environment." The Global Village: Transformations in World Life and Media in the 21st Century. New York, NY: Oxford University Press, 1989. pp. 147-166.

Mellencamp, Patricia. Indiscretions: Avant-Garde Film, Video, \& Feminism.

Bloomington, IN: Indiana University Press, 1990.

Merleau-Ponty, Maurice. Phenomenology of Perception. Colin Smith (trans). London, UK: Routledge, 1962.

Sense and Non-Sense. Hubert L. and Patricia Allen Dreyfus (trans). Chicago, IL: Northwestern University Press, 1964.

Michelson, Anne. "Toward Snow." Artforum. Nos. 9/10, June 1971. pp. 30-37.

Niedzviecki, Hal. We Want Some Too: Underground Desire and the Reinvention of Mass Culture. Toronto, ON: Penguin Books Ltd, 2000.

Petersen, James. Dreams of Chaos, Visions of Order: Understanding the American Avant-Garde Cinema. Detroit, MI: Wayne State University Press, 1994.

"Is a Cognitive Approach to the Avant-Garde Cinema Perverse?". In David Bordwell and Noel Carroll (eds). Post-Theory: Reconstructing Film Studies. Madison, WI: University of Wisconsin Press, 1996. pp.108-129.

Poissant, Louise. "Video: Writing History." In Peggy Gale and Lisa Steele (eds). Video reView: The (best) Source For Critical Writings on Canadian Artists' Video. Toronto, ON: Art Metropole and Vtape, 1996 [1994]. pp. 190-194. 
Polan, Dana B. The Political Language of Film and the Avant-Garde. Ann Arbor, MI: UMI Research Press, 1985.

Quince, Donna and Jose Sanchez (eds). Queering Canada: A Collection of Essays. Ottawa, ON: Making Scenes/Canada Council for the Arts, 2000.

Ramadori, Maria. Sensible Bodies: feminist experimental cinema and embodied subjectivities. Ottawa, ON: Carleton University, 2000. (Master's Thesis).

Reinke, Steve and Tom Taylor (eds). Lux: A Decade of Artists' Film and Video. Toronto, ON: Pleasure Dome and YYZ Books, 2000.

Rees, A.L. A History of Experimental Film and Video: From the Canonical AvantGarde to Contemporary British Practice. London, UK: British Film Institute, 1999.

Rinehart, James W. The Tyranny of Work: Alienation and the Labour Process. (3rd Edition). Toronto, ON: Harcourt Brace and Company Ltd, 1996.

Renov, Michael and Erika Suderberg. Resolutions: Contemporary Video Practices. Minneapolis, MN: University of Minnesota Press, 1996.

Rodowick, D.N. Gilles Deleuze's Time Machine. Durham, NC: Duke University Press, 1997.

Rosler, Martha. "Video: Shedding the Utopian Moment." In Doug Hall and Sally Jo Fifer (eds). Illuminating Video: An Essential Guide to Video Art. New York, NY: Aperture/Bay Area Video Coalition, 1990. pp. 31-50.

Rush, Michael. New Media in Late 20th-Century Art. London, UK: Thames \& Hudson, 1999.

Russell, Catherine. Experimental Ethnography: The Work of Film in the Age of Video. Durham, NC: Duke University Press, 1999.

Sandlos, Karyn and Mike Hoolboom (eds). Landscape With Shipwreck: first person cinema and the films of Philip Hoffman. Toronto, ON: Images Festival of Independent Film and Video/Insomniac Press, 2001.

Schneider, Ira and Beryl Korot. Video Art: An Anthology. New York, NY: Harcourt Brace Jovanovich/Raindance Foundation, 1976.

Small, Edward S. Direct Theory: Experimental Film as Major Genre. Carbondale, IL: Southern Illinois University Press, 1992. 
Sobchack, Vivian. The Address of the Eye: Phenomenology and the Film Experience. Princeton, NJ: Princeton University Press, 1992.

Steele, Lisa. "Committing Memory." Vera Frenkel: The Videotapes. Ottawa, ON: National Gallery of Canada, 1985.

Sudre, Alain-Alcide. "In Favour of an Exploratory Practice." In Rose Lowder (ed). The Visual Aspect: Recent Canadian Experimental Films. Editions des Archives du Film Experimental d'Avignon, 1991. pp. 55-66.

Tuer, Dot. "Mirroring Identities: Two Decades of Video Art in English Canada." In Janine Marchessault (ed). Mirror Machine: Video and Identity. Toronto, $\mathrm{ON}$ : YYZ Books \& CRCCII, 1995. pp. 107-125.

Turim, Maureen Cheryn. Abstraction in Avant-Garde Films. Ann Arbor, MI: UMI Research Press, 1985.

Varga, Darrell. "In/Between Spaces." In Karyn Sandlos and Mike Hoolboom (eds). Landscape with Shipwreck: first person cinema and the films of Philip Hoffman. Toronto, ON: Images Festival of Independent Film and Video/Insomniac Press, 2001. pp. 109-123.

"Panic Bodies and the Performance of Space." Canadian Journal of Film Studies. Vol. 10:2, 2002. pp. 80-101.

Wees, William C. "The Camera, The Eye and The Visual Aspect of Canadian AvantGarde Film." In Rose Lowder (ed). The Visual Aspect: Recent Canadian Experimental Films. Editions des Archives du Film Experimental d'Avignon, 1991. pp. 13-19.

"Carrying On: Leslie Thornton, Su Friedrich, Abigail Child and American AvantGarde Film of the Eighties." Canadian Journal of Film Studies. Vol. 10:1, 2001. pp.70-95.

Light Moving in Time: Studies in the Visual Aesthetics of Avant-Garde Film. Berkeley, CA: University of California Press, 1992.

Wilden, Tony. The Imaginary Canadian: An Examination For Discovery. Vancouver, BC: Pulp Press, 1980.

Williams, Linda. "Melodrama Revisited." In Hick Brown (ed). Refiguring American Film Genres. Berkeley, CA: University of California Press, 1998. pp. 42-88. 


\section{Appendix: Films and Videos Screened}

\begin{tabular}{|c|c|}
\hline Kay Armatage & Speakbody $(1979,16 \mathrm{~mm}$ film, $7 \mathrm{~min})$. \\
\hline Shauna Beharry & Seeing is Believing (1991, video, 8 min.) \\
\hline Jubal Brown & $\begin{array}{l}\text { The Blob (1999, video, } 9 \text { min.) } \\
\text { The Star Wars \& Ad Death (1998, video, } 2 \text { min.) }\end{array}$ \\
\hline Natalie Bujold & Emporium (1999, video, $12 \mathrm{~min})$. \\
\hline Colin Campbell & $\begin{array}{l}\text { Rendez-Vous (1997, video, } 13 \mathrm{~min} .) \\
\text { Sackville I'm Yours (1972, video, } 14 \mathrm{~min} .) \\
\text { Skin (1990, video, } 18 \mathrm{~min} .) \\
\text { True/False (1972, video, } 15 \mathrm{~min} .) \\
\text { Hollywood and Vine (1976, video, } 18 \mathrm{~min} .)\end{array}$ \\
\hline Shawn Chapelle & Trans $(1995$, video, $5 \mathrm{~min})$. \\
\hline Dana Claxton & Buffalo Bone China $(1996$, video, $10 \mathrm{~min})$. \\
\hline Aleesa Cohene & $\begin{array}{l}\text { Abscess (2001, video, 10:20 min.) } \\
\text { Absolutely (2001, video, 8:25 min.) }\end{array}$ \\
\hline Norman Cohn & $\begin{array}{l}\text { In my end is my beginning, Part Two: Lucy Brown } \\
\text { (1982, video, } 38 \text { min.) }\end{array}$ \\
\hline Donigan Cumming & A Prayer for Nettie (1995, video, 33 min.) \\
\hline $\begin{array}{l}\text { Shawna Dempsey \& } \\
\text { Lorri Millan }\end{array}$ & Subject/Object of Desire (1993, video, 5:15 min.) \\
\hline $\begin{array}{l}\text { Emily vey Duke \& } \\
\text { Cooper Battersby }\end{array}$ & $\begin{array}{l}\text { Being Fucked Up }(2000, \text { video, } 13 \mathrm{~min} .) \\
\text { The Fine Arts }(2001, \text { video 3:40 min.) } \\
\text { Rapt and Happy }(1998, \text { video, } 17 \mathrm{~min} .)\end{array}$ \\
\hline Stan Douglas & $\begin{array}{l}\text { Television Spots }(1987 / 88, \text { video, } 4: 30 \mathrm{~min} .) \\
\text { Win, Place or Show }(1998 \text {, video installation, } 5 \mathrm{~min} \text {.) }\end{array}$ \\
\hline Karen Earl & Rancour (2000, video, $8 \mathrm{~min})$. \\
\hline R. Bruce Elder & $\begin{array}{l}\text { 1857: Fool's Gold (1981, 16mm film, } 24 \mathrm{~min} .) \\
\text { She Is Away (An Arrangement in Blue and Pink) } \\
(1975,16 \mathrm{~mm} \text { film, } 13 \mathrm{~min} .)\end{array}$ \\
\hline
\end{tabular}


Ellie Epp

Bridget Farr

Pierre Falardeau

Marcel Fayant

Nikki Forrest

Vera Frenkel

Richard Fung

John Greyson

Patricia Gruben

Richard Hancox

Phil Hoffman

David Hoffos
Trapline (1975, 16mm film, $20 \mathrm{~min}$ )

Notes in Origin (1987, $16 \mathrm{~mm}$ film, $20 \mathrm{~min}$.)

Nobody's Nothing (1999, 35mm film, 4 min.)

Continuons le Combat (1970, video, 31 min.)

In Response to the Dumbest Question of the 20th Century

(1999, video, 3:30 min.)

Shift (1997, video, 9 min.)

Censored: The Business of Frightened Desires

(1987, video, $25 \mathrm{~min}$.)

This Is Your Messiah Speaking (1991, video, $10 \mathrm{~min}$.

Introduction To Some Of The Players (1977, video, $22 \mathrm{~min}$.)

The Secret Life of Cornelia Lumsden: A Remarkable Story,

Part Two... And Now The Truth (A Parenthesis)

(1980, video, $31 \mathrm{~min}$.)

Chinese Characters (1986, video, 20:30 min.)

Dirty Laundry (1997, video, $31 \mathrm{~min}$.)

Fighting Chance (1990, video, $31 \mathrm{~min}$.)

My Mother's Place (1990, video, $49 \mathrm{~min}$.)

Sea in the Blood (2000, video, $26 \mathrm{~min}$.)

The Jungle Boy (1986, video, 15:30 min.)

The Making of Monsters (1991, video, $35 \mathrm{~min}$.)

Pack'n (2001, video, 4 min.)

The Central Character (1977, 16mm film, $16 \mathrm{~min}$.)

Sifted Evidence $(1982,16 \mathrm{~mm}$ film, $42 \mathrm{~min}$.)

Home for Christmas (1978, $16 \mathrm{~mm}$ film, $47 \mathrm{~min}$.)

Landfall $(1993,16 \mathrm{~mm}$ film, $9 \mathrm{~min}$.)

Moose Jaw (There's a Future in Our Past)

(1990, $16 \mathrm{~mm}$ film, $54 \mathrm{~min}$.)

Chimera (1996, 16mm film, $15 \mathrm{~min}$.

Kitchener-Berlin (1990, 16mm film, $34 \mathrm{~min}$.)

?O Zoo! The Making of A Fiction Film (1986, 16mm, $23 \mathrm{~min}$.)

What These Ashes Wanted (2001, 16mm film, $56 \mathrm{~min}$.)

Disaster (2000, video, 4 min.) 
Mike Hoolboom

Simon Hughes

Vern Hume

Dana C. Inkster

Donna James

Istvan Kantor

Richard Kerr

Gary Kibbins

Manon Labreque

Robert Lee

Paula Levine

Zachery Longboy
Frank's Cock (1993, 16mm film, $8 \mathrm{~min}$.)

In The Family Car (1994, 16mm film, 4 min.)

Justify My Love (1994, video, 5 min.)

Kanada $(1993,16 \mathrm{~mm}$ film, $63 \mathrm{~min}$.)

Letters From Home (1991, 16mm film, $15 \mathrm{~min}$.)

Aexieo with Steve Sanguedolce (1992, 16mm film, $35 \mathrm{~min}$.)

Panic Bodies (1998, 16mm film, $75 \mathrm{~min}$.)

Positiv (1998, video, 9 min.)

Was $(1989,16 \mathrm{~mm}$ film, $14 \mathrm{~min}$.

White Museum (1986, 16mm film, $32 \mathrm{~min}$.)

Awakening of Desire (1997, video, $4 \mathrm{~min}$.)

Buck with Leila Sujir (1986, video, $25 \mathrm{~min}$.)

Lamented Moments/Desired Objects (1988, video, $14 \mathrm{~min}$.)

Vacation/Vacances with Leila Sujir (1986, video, $13 \mathrm{~min}$.)

Welcome to Africville (1997, video, $13 \mathrm{~min}$.)

Maigre Dog (1990, video, $8 \mathrm{~min}$.)

The Thickness of Guidance (1998, video, $4 \mathrm{~min}$.)

Accumulations (1999, video, 9 min.)

Black Flag (1997, video, 7 min.)

Jericho (1991, video, $17 \mathrm{~min}$.)

Canal (A Place In Our Youth) (1981, 16mm film, $22 \mathrm{~min}$.)

I Was a Strong Man Until I Left Home (2000, video, 45 min.)

Last Days of Contrition (1988, 16mm film, $36 \mathrm{~min}$.)

On Land Over Water (Six Stories) (1984, 16mm film, $59 \mathrm{~min}$.)

Plein Air (1991, 16mm film, $20 \mathrm{~min}$.)

The Alien Seaman (1998, video, $20 \mathrm{~min}$.)

Carl Andre's Overalls (2000, video, $11 \mathrm{~min}$.)

Mead Lake (1992, video, $28 \mathrm{~min}$.)

$P \& \operatorname{Not}-P(1994$, video, $27 \mathrm{~min}$.)

On This Side of the Real (1997, video, $12 \mathrm{~min}$.)

$A K-47(1999$, video, 6 min. $)$

Mirror Mirror (1987, video, 3 min.)

Confirmation of My Sins (1995, video, $12 \mathrm{~min}$.)

the stone show $(1999$, video, $9 \mathrm{~min}$.) 
Janine Marchessault The Act of Seeing with Another Eye (1990, video, 20 min.) Numerology of Fear (1998, video, $18 \mathrm{~min}$.)

Wrik Mead $\quad$ Camp $(2000,16 \mathrm{~mm}$ film, $14 \mathrm{~min}$.

Hand Job (2001, 16mm film, $2 \mathrm{~min}$.)

Monique Moumblow Joan and Stephen (1996, video, 12 min.)

Sleeping Car (2000, video, $5 \mathrm{~min}$.)

Ian Murray $\quad$ Come On Touch It (1984, video, 33 min.)

Keeping on Top of the Top Song (1973, video, $18 \mathrm{~min}$.)

Nova Boetia: Another World (1976, video, $20 \mathrm{~min}$.)

Jan Peacock

WHITEWASH (1990, video, 14:30 min.)

Sisi Penalozo

Thumper (2000, video, $6 \mathrm{~min}$.)

Grant Poier

Interrupted Attempt (1986, video, $4 \mathrm{~min}$.)

Gary Popovich

Antigone $(1990,16 \mathrm{~mm}$ film, $8 \mathrm{~min}$.)

Archaeology of Memory (1992, 16mm film, $14 \mathrm{~min}$.)

Faultines (1997, 16mm film, $22 \mathrm{~min}$.)

Doug Porter

I'd Like to Move On If I Could Please (1990, video, 5 min.) Losing Sleep (1996, video, 14 min.)

Run Into Peace (1998, video, $11 \mathrm{~min}$.)

Time Has No Image (1991, video, 8:30 min.)

Benjamin Nemerofsky Ramsay

Je Changerais $d^{\prime}$ Avis (2000, video, 4 min.)

Al Razutis

98.3 KHz (Bridge at Electrical Storm) (1973, video, 11:30 min.)

Steve Reinke

The 100 Videos (1990-1995, video excerpts, 4 hrs \& 44 mins.)

Afternoon (March 22, 1999) (1999, video, $23 \mathrm{~min}$.)

Echo Valley (1998, video, 7:15 min.)

Everybody Loves Nothing (1996, video, 12 min.)

Fireball (1999, video, 4 min.)

David Rimmer Fracture $(1973,16 \mathrm{~mm}$ film, $10 \mathrm{~min}$ )

Susan C. Rynard $1932(1988$, video, $8 \mathrm{~min}$.)

Absence (1986, video, $6 \mathrm{~min}$.)

The Day Jesus Melted (1999, video, 3:15 min.)

Eight Men Called Eugene (1996, video, $12 \mathrm{~min}$.)

Signal (1993, video, $3 \mathrm{~min}$.) 
What Wants To Be Spoken, What Remains To Be Said (1992, video, $25 \mathrm{~min}$.)

Within Dialogue (Silence) (1987, video, 5:30 min.)

Jayce Salloum

The Ascent of Man I, II, III (1986/87, video, $19 \mathrm{~min}$.

Steve Sanguedolce Sweetblood $(1993,16 \mathrm{~mm}$ film, $13 \mathrm{~min}$.)

Cathy Sisler

The Lullaby of the Almost Falling Woman

(1996, video, $14 \mathrm{~min}$.)

Twala (1995, video, $20 \mathrm{~min}$.)

Rae Staesson

Slang (1994, video, 4:30 min.)

Lisa Steele

The Ballad of Dan Peoples (1976, video, 8 min.)

Birthday Suit With Scars \& Defects (1974, video, 12 min.)

The Blood Records with Kim Tomczak (1997, video, 50 min.)

Facing South (1975, video, $22 \mathrm{~min}$.)

Some Call It Bad Luck (1982, video, $47 \mathrm{~min}$.)

Talking Tongues (1982, video, 11 min.)

Barbara Sternberg At Present (1990, 16mm film, $18 \mathrm{~min}$.)

Like a Dream That Vanishes $(2000,16 \mathrm{~mm}$ film, $60 \mathrm{~min}$.)

Ho Tam

$99 \operatorname{Men}(1998$, video, 3 min.)

Kika Thorne

Intraduction (1998, video, 2:30 min.)

October $25 \& 261996$ (1996, video, 6 min.)

Sister (1995, video, $11 \mathrm{~min}$.)

The Up and the Down (2001, video, 5:30 min.)

Work (1999, video, 9:30 min.)

Yearbook (1997, video, $3 \mathrm{~min}$.)

Ross Turnbull

Fierce Tears (1998, video, 6:30 min.)

John Watt

Industrial Track Part 2: Surveillance On The Welland Canal (1985, video, $25 \mathrm{~min}$.)

Nuclear Breakdown (1984, video, 9 min.)

Rodney Werden $\quad$ Kiss/Kiss (1975, video, $3 \mathrm{~min}$.)

May I/Can I (1977, video, $6 \mathrm{~min}$.)

Say $(1976$, video, 3:30 min.)

Typist (1978, video, 18:30 min.) 